\title{
Modeling and performance analysis of biomass fast pyrolysis in a solar-thermal reactor
}

\author{
Muktar Bashir ${ }^{\mathrm{a}}, \mathrm{Xi} \mathrm{Yu}^{\mathrm{a}}$, Mohamed Hassan ${ }^{\mathrm{b}}$, Yassir Makkawi ${ }^{\mathrm{c}, *}$ \\ a European Bioenergy Research Institute (EBRI), School of Engineering and Applied Science, \\ Aston University, Birmingham, B4 7ET, UK \\ ${ }^{\mathrm{b}}$ Chemical Engineering Department, Faculty of Engineering, Jazan University, P.O. Box 114, \\ Jazan, KSA \\ ${ }^{\mathrm{c}}$ Chemical Engineering Department, College of Engineering, American University of Sharjah, \\ P.O. Box 26666, Sharjah, United Arab Emirates.
}

\begin{abstract}
Solar-thermal conversion of biomass through pyrolysis process is an alternative option to store energy in the form of liquid fuel, gas and bio-char. Fast pyrolysis is a highly endothermic process and essentially requires high heating rate and temperature $>400{ }^{\circ} \mathrm{C}$. This study presents a theoretical study on biomass fast pyrolysis in a solar-thermal reactor heated by a parabolic trough concentrator. The reactor is part of a novel closed loop pyrolysis-gasification process. A Eulerian-Eulerian flow model, with constitutive closure equation derived from the kinetic theory of granular flow and incorporating heat transfer, drying and pyrolysis reaction equations, was solved using ANSYS Fluent computational fluid dynamics (CFD) software. The highly endothermic pyrolysis was assumed to be satisfied by a constant solar heat flux concentrated on the reactor external wall. At the operating conditions considered, the reactor overall energy efficiency was found equal to $67.8 \%$ with the product consisting of $51.5 \%$ biooil, $43.7 \%$ char and $4.8 \%$ non-condensable gases. Performance analysis is presented to show the competitiveness of the proposed reactor in terms of thermal conversion efficiency and environmental impact. It is hoped that this study will contribute to the global effort on securing diverse and sustainable energy generation technologies.
\end{abstract}

Keywords: solar conversion, biomass fast pyrolysis, CFD modeling, parabolic trough, sustainable energy, bio-fuel

\footnotetext{
*Corresponding author: Tel.: +97165152167; fax: +97165152979. E-mail address: ymakkawi@aus.edu (Yassir T. Makkawi).
} 


\title{
Modeling and performance analysis of biomass fast pyrolysis in a solar- thermal reactor
}

\author{
Muktar Bashir ${ }^{\mathrm{a}}$, Xi Yuª ${ }^{\mathrm{a}}$ Mohamed Hassan ${ }^{\mathrm{b}}$, Yassir Makkawi c,*
}

\section{Table of Contents}

Abstract

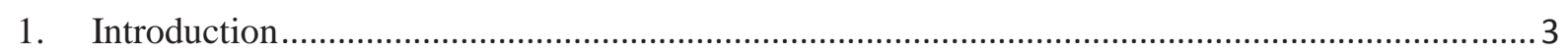

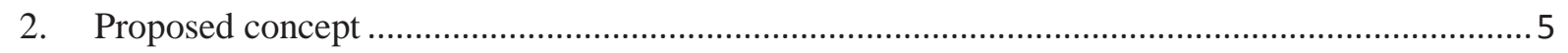

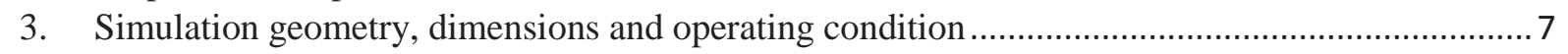

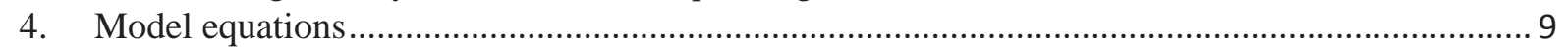

4.1. Continuity, momentum and granular energy equations .................................................... 9

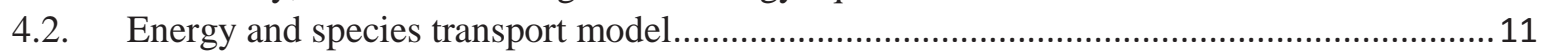

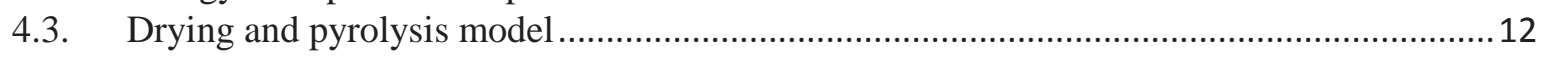

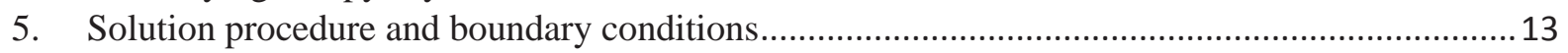

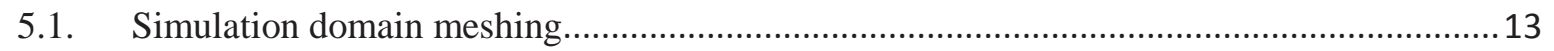

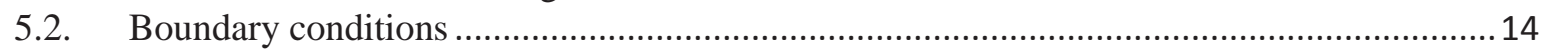

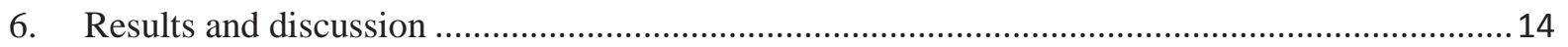

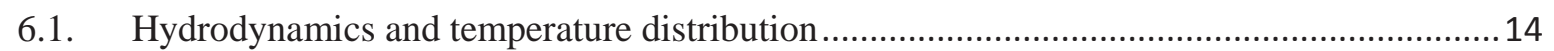

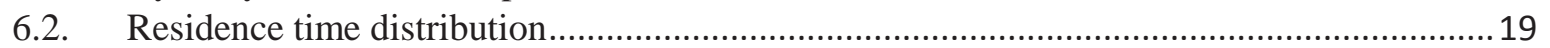

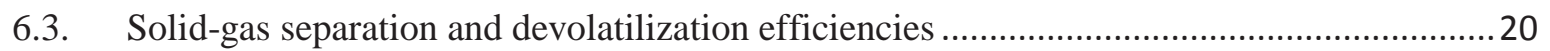

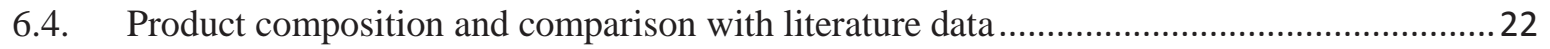

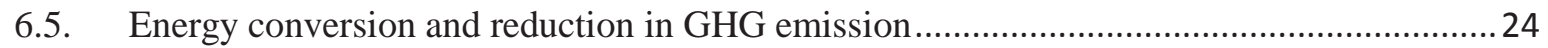

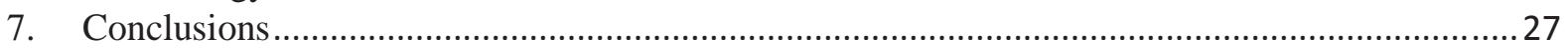

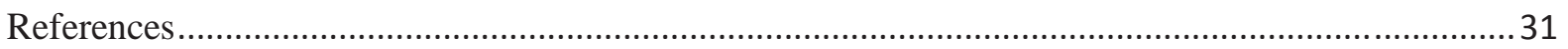

\section{Graphic Abstract}

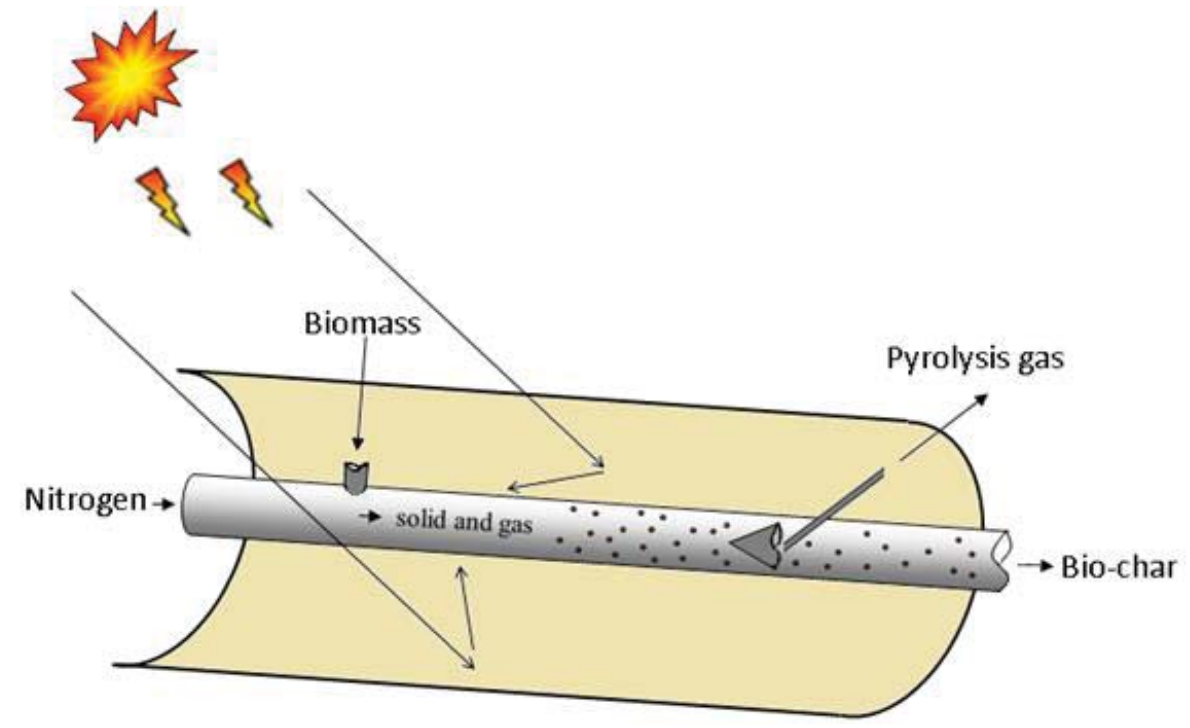

Synopsis: A model of biomass pyrolysis in a solar-thermal reactor is presented to show the potential of the concept for sustainable energy.

\footnotetext{
*Corresponding author: Tel.: +97165152167; fax: +97165152979. E-mail address: ymakkawi@aus.edu (Yassir T. Makkawi).
} 


\section{Introduction}

The global climate change and the associated environmental concerns has led to the ongoing research on renewable and clean energy resources. Solar-thermal is an attractive and unlimited source of a renewable energy with potentially net zero carbon footprint. Similarly, biomass is another attractive energy source that has recently received increasing interest as a source of bio-fuels (liquid oil and gas). According to the International Energy Agency (IEA) the current total contribution from solar and biomass resources to the total world energy supply is only $<1.5 \%$ and $<10.5 \%$, respectively. ${ }^{1,2}$ However, both sources are predicted to play a major role in securing future energy supply. Some reports suggest that the world's bioenergy potential from wood fuel is large enough to satisfy the global demand by $2050 .^{2}$ It is also estimated that, covering $\sim 0.1 \%$ of the world's land space with solar collectors at $\sim 20 \%$ collection efficiency can generate enough energy to supply the current world's demand. ${ }^{3}$ However transferring theses energy recourses to direct usable, storable and transportable energy is still a subject of ongoing research.

Clearly, a technology that combines the two most abundant energy resources, that are solar and biomass, would be highly attractive. One of the basic paths to do so is the so-called "Solar Thermochemical Process". Solar thermochemical conversion of biomass can provides long term solar storage while converting the chemicals to high density fuels. Here, it is proposed that a concentrated solar heat can be used to drive the highly endothermic biomass pyrolysis reaction, which in turn produces a high density energy in the form of bio-oil in addition to gas and char. Historically, solar-biomass conversion is not new and the earlier attempts on this goes back to the mid 70's. Antal ${ }^{5,6,7,8}$ was one of the first researchers to report experimental results of biomass fast and slow pyrolysis under various concentrated solar radiation intensities. This pioneering work was then followed by numerous experiments on various types of solar reactors for the transformation of various carbonaceous materials to fuel (e.g. Ingel et al.; ${ }^{9}$ Steinfeld and Fletcher; ${ }^{10}$ Fletcher; ${ }^{11}$ Steinfeld and Palumbo ${ }^{12}$ ).

One of the most widely used solar concentration technology is the parabolic trough system. The technology is simply based on redirection of solar radiation by a set of curved mirrors (parabola) to a small tubular receiver/collector located along the focal line. The tube is usually coated with high absorptive material and enveloped by a transparent glass to minimize heat losses. The concentrated solar heat facilitates high temperatures and high heating rate of the 
working fluid. ${ }^{13,14} \mathrm{~A}$ working fluid such as water, oil or molten salt is used to store and transfer the concentrated solar thermal in power plants. This technology has recently received increasing attention in solar thermochemical processing. Jin et al. ${ }^{15}$ reported experimental work involving methanol decomposition in a solar receiver tube as part of a parabolic trough system. The process was reported to achieve 30-60\% efficiency in solar thermal conversion to chemical energy. Sui et al. ${ }^{16}$ also reported a similar experiment on solar decomposition of methanol at $\mathrm{mid} /$ low temperature range of $200-300^{\circ} \mathrm{C}$ to further confirm the great potential of this concept. Despite of this, so far, studies on hybrid solar-thermal pyrolysis based on parabolic trough system are scarce. Morales et al. ${ }^{17}$ reported one of the very few experimental attempts on biomass pyrolysis in a parabolic trough receiver. The reactor was operated at a fixed bed mode at the temperature of $465{ }^{\circ} \mathrm{C}$ with the biomass packed in the receiver prior to its positioning in the concentrator focal line. Using a different approach, Anderson et al. ${ }^{18}$ carried out experiment on solar biomass pyrolysis in an auger conveyer/reactor heated by a parabolic trough concentrator. The auger system has the advantage of producing ablative effect, but at the same time, increases the residence time of both solid and gas, which result in shifting the process towards slow pyrolysis (i.e. more char and less bio-oil). An augur system also carries the considerable risk of metal expansion and reactor blockage, which makes it difficult to implement in real practise. In another different approach, Boutin et al. ${ }^{19}$ used an image furnace system, which mainly consist of elliptical mirrors concentrating radiant flux on a focal point, to study the flash pyrolysis of a cellulose sample placed inside a transparent quartz reactor. The experiment used direct absorption radiation produced artificially by a concentrated light. The problem associated with the direct radiation (non-ablative) is the possible interception of the incoming radiation caused by evolved liquid and solids depositing on the radiation screen. Also, biomass has high reflectivity and low absorbing optical properties, which result in producing high char rather than bio-oil. ${ }^{20}$

Due to the great improvement in computational hardware and software, computational fluid dynamic (CFD) models are nowadays capable of predicting multiphase flow and heat transfer to a high accuracy and on various scales of engineering processes. This reduces the cost of pilot scale experimentations and provides data necessary for accurate design and development. CFD models predicting the hydrodynamics and heat transfer characteristics of fluid flow in a parabolic trough receiver have been frequently reported in the literature (e.g. Wattana et al. ${ }^{21}$ ). The CFD modeling can be extended to reactive systems if the equations describing the thermochemical reactions and hydrodynamics are coupled and solved. For example, Xue et 
To the best of the author's knowledge, so far there have been no studies done on solar pyrolysis of biomass suspension in a parabolic trough receiver/reactor, but there are studies related to solar biomass conversion, as noted above, including a patent (current status: withdrawn) on solar biomass conversion in a parabolic trough receiver by Storey and Monceaux ${ }^{25}$. This study presents the first comprehensive CFD model and performance analysis (hydrodynamics and thermochemical) of biomass pyrolysis in a solar reactor/receiver as part of a novel closed-loop process for biomass conversion to fuels (bio-oil and fuel gas). The focus here is mainly on the reactor performance without going into the details of the solar collection or its efficiency. The model was solved using ANSYS FLUENT CFD software (Ver 15) and in-house developed user-defined function for the pyrolysis reaction scheme. The overall objectives of the study are two folds: (i) demonstrate the potential of the proposed concept for efficient, environmental friendly and sustainable production of bio-fuel from biomass pyrolysis (ii) present a valid computational tool for future development and scale up of the proposed reactor.

\section{Proposed concept}

Pyrolysis is a well-established process for the thermal decomposition of biomass in an oxygen free atmosphere. The process primarily produces a gas phase, commonly referred to as pyrolysis gas, and char. Upon rapid cooling to standard temperature and pressure (quenching), the pyrolysis gas reduces to condensable and non-condensable fractions. The condensable fraction is known as bio-oil (heavy hydrocarbons) and its fraction/composition compared to the char and non-condensable gas strongly depend on the temperature, heating rates and residence time used. In fast pyrolysis, which is relevant to this study, the recommended heating 
rate and residence time of the gas phase are in the ranges of $100-10^{5}{ }^{\circ} \mathrm{C} / \mathrm{s}$ and $1-2 \mathrm{~s}$, respectively. ${ }^{4}$ In order to increase the bio-oil yield, it is essential to (i) keep the reactor temperature within the recommended temperature range of $400-550{ }^{\circ} \mathrm{C}$ and (ii) avoid overcracking of the pyrolysis gas by keeping the gas residence time below $2 \mathrm{s.}^{4}$ It is also recommended to limit the contact between the pyrolysis gas and char to avoid catalytic cracking of the heavy hydrocarbons. ${ }^{26}$

Figure 1 shows a schematic diagram of the overall proposed concept of a hybrid solar-thermal conversion of biomass to bio-oil and hydrogen-rich fuel gas. In this process, biomass particulate is introduce to a tubular reactor/receiver located at the focal point of a parabolic trough collector to produce a pyrolysis gas through rapid thermal decomposition (drying and devolatilization). It is proposed to utilize the non-condensable gases (mainly $\mathrm{H}_{2}, \mathrm{CO}, \mathrm{CO}_{2}$ and $\mathrm{CH}_{4}$ ) and the solid (bio-char), which is assumed to contain the remaining volatiles, fixed carbon and some minerals, in the production of a hydrogen-rich fuel gas via steam gasification in a circulating fluidized bed (CFB) reactor.

In this paper, focus is made on the tubular solar receiver/reactor only, as detailed in Figure 1b. The gasification of char in the CFB, shown in the right side of Figure 1a, will be the subject of the second part of this study. At the inlet to the solar receiver/reactor, which shall be referred to as the reactor in the rest of this paper, a pre-heated inert gas (nitrogen) is introduced at the appropriate velocity and temperature to fluidize the biomass and convey it towards the exit. In principle, the carrier gas can be pre-heated by solar heat before entering the reaction section (this is out of the scope of this study). The biomass undergoes rapid pyrolytic conversion to produce a pyrolysis gas and solid (bio-char). The highly endothermic pyrolysis reaction will mainly be sustained by the concentrated solar radiation focused at the reactor wall. The pyrolysis gas is separated from the solid phase and removed from the reactor using an in situ gas-solid separation mechanism. The mechanism mainly consists of a conical flow deflector that allows for the discharge of the gas-free solid through an inserted pipe. This novel separation mechanism was first reported by Huard et al. ${ }^{27}$ for the application in downer reactors and recently have been applied by Yu et al. ${ }^{28,} 29$ in numerical studies of biomass pyrolysis in a similar reactor. Unlike conventional gas-solid separation by cyclones, this separation mechanism has the advantage of better control of the pyrolysis gas residence time while limiting the contact between the char and the pyrolysis gas after formation. Such a control is important to avoid thermal and catalytic cracking of the gas, since both could adversely affect 
the bio-oil yield. Reported studies suggest that thermal over cracking occurs if the gas residence time within the hot zone of the reactor exceeds $2 \mathrm{~s}$, while catalytic cracking result from excessive contact between the gas and bio-char. ${ }^{32}$
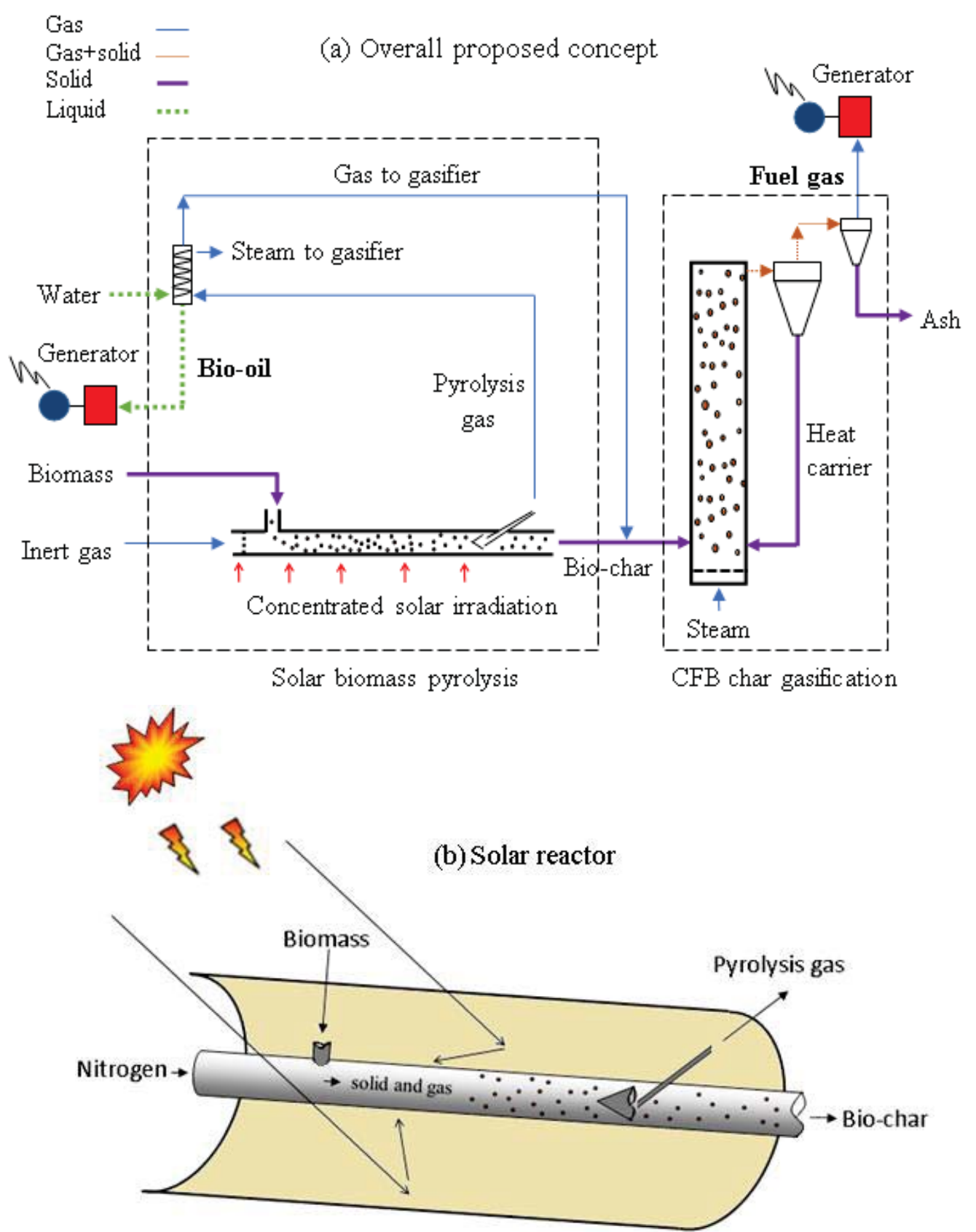

Figure 1. Proposed concept (a) Closed-loop solar pyrolysis integrated with gasification process (b) Details of the solar pyrolysis reactor and the gas-solid separation mechanism

\section{Simulation geometry, dimensions and operating condition}

The geometry and dimensions of the simulation domain are shown in Figure 2. This mainly consist of a tubular reactor equipped with a gas-solid separator in addition to a solid receiving 
tank. The multiphase flow in the domain consists of a particulate phase (biomass) and a gas phase. The biomass material considered is switch grass with the approximate and ultimate composition as given in Table 1.

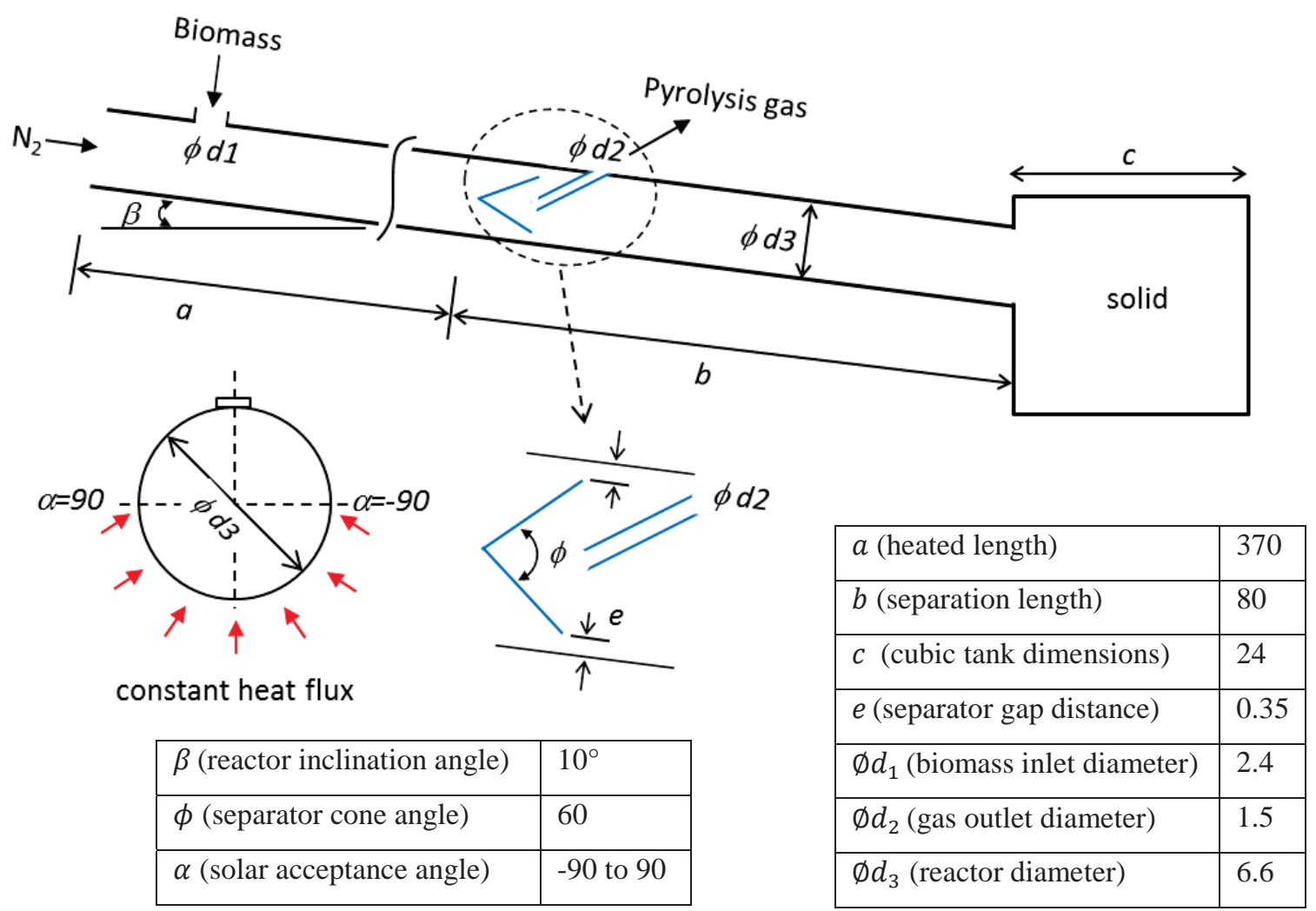

Figure 2. Geometry, orientation and dimensions of the solar pyrolysis reactor and solid receiving tank (all dimensions are in centimetres).

A constant solar heat flux, focused on the lower half of the reactor wall is used to supply the heat required to sustain the highly endothermic pyrolysis reaction. The heated section and the solid separation section, designated $a$ and $b$ in Figure 2, make the total reactor length of $4.4 \mathrm{~m}$. The reactor is slightly inclined from horizontal by $10^{\circ}$ to mimic the operating condition in real practise. This also has the advantage of enhancing the multiphase flow by gravity, hence allow reducing the amount of carrier gas required to drag the solid phase. As shown in Figures 1 and 2 , the solid-gas separator takes the shape of a rigid empty cone, which allows deflection of the multiphase flow towards the gap between the wall and the edge of the cone. This creates a low pressure zone within the inner of the cone through which the gas-free solid is removed via the inserted gas pipe. Further details on this solid-gas separation mechanism and its application in pyrolysis reactors can be found in Huard et al. ${ }^{27}$ and Yu et al. ${ }^{28,29}$. The summary of the reactor operating conditions are given in Table 2. 
Table 1. Proximate and ultimate analysis of switch grass. ${ }^{30}$

\begin{tabular}{c|ccccc}
\hline \multirow{2}{*}{ Proximate analysis $(\mathrm{wt} \%)$} & Moisture & Volatile & Ash & Fixed carbon & HHV (MJ/kg) \\
& 2.65 & 81.20 & 2.54 & 13.81 & 19.06 \\
\hline \multirow{2}{*}{ Ultimate analysis $(\mathrm{wt} \%)$} & $\mathrm{C}$ & $\mathrm{H}$ & $\mathrm{O}$ & $\mathrm{N}$ & $\mathrm{S}(\mathrm{ppm})$ \\
& 48.8 & 6.99 & 43.68 & 0.53 & 0 \\
\hline
\end{tabular}

Table 2. Summary of the reactor dimensions and operating conditions

\begin{tabular}{ll}
\hline Parameter & Operating condition \\
\hline Biomass particle diameter $(\mu \mathrm{m})$ & 500 \\
Biomass and nitrogen feed temperature $\left({ }^{\circ} \mathrm{C}\right)$ & 27 and 400, respectively \\
Biomass and nitrogen feed rate $\left(\mathrm{g} \mathrm{s}^{-1}\right)$ & 2.0 and 3.9, respectively \\
Solar hear flux at the reactor wall $\left(\mathrm{kW} \mathrm{m}^{-2}\right)$ & 12.55 \\
\hline
\end{tabular}

\section{Model equations}

The multiphase flow hydrodynamics was modelled using the two fluid approach (EulerianEulerian) with the main constitutive equations based on the kinetic theory of granular flow (KTGF). The model was then coupled with the heat transfer, mass transfer and thermochemical equations required to predict the overall reactor performance and composition of the products from the pyrolysis process.

\subsection{Continuity, momentum and granular energy equations}

The continuity equations for the gas and solid phases are given as follows:

$$
\begin{aligned}
& \frac{\partial}{\partial t}\left(\alpha_{g} \rho_{g}\right)+\nabla\left(\alpha_{g} \rho_{g} \vec{v}_{g}\right)=\vec{R}_{g} \\
& \frac{\partial}{\partial t}\left(\alpha_{s} \rho_{s}\right)+\nabla\left(\alpha_{s} \rho_{s} \vec{v}_{s}\right)=\vec{R}_{s} \\
& \alpha_{s}+\alpha_{g}=1
\end{aligned}
$$

where the terms in the left side of eqs 1 and 2 represent the transient mass transport, $\vec{R}$ represent the exchange due to mass transfer of species (reaction and evaporation), $\vec{v}$ is the velocity vector, $\alpha$ is the volume fraction and $\rho$ is the density. The subscripts $s$ and $g$ refer to the solid and gas phases respectively. 
The momentum equations for the gas and solid phases are based on Newton's second law as follows:

$$
\begin{aligned}
\frac{\partial}{\partial t}\left(\alpha_{g} \rho_{g} \vec{v}_{g}\right)+ & \nabla\left(\alpha_{g} \rho_{g} \vec{v}_{g} \vec{v}_{g}\right) \\
& =-\alpha_{g} \nabla P+\nabla \overline{\bar{\tau}}_{g}-\beta\left(v_{g}-v_{s}\right)+\alpha_{g} \rho_{g} \vec{g} \cos \theta+\dot{m}_{s g} \vec{v}_{s g}+\vec{R}_{s g} \\
\frac{\partial}{\partial t}\left(\alpha_{s} \rho_{s} \vec{v}_{s}\right)+ & \nabla\left(\alpha_{s} \rho_{s} \vec{v}_{s} \vec{v}_{s}\right) \\
& =-\left(\alpha_{s} \nabla P+\nabla P_{s}\right)+\nabla \overline{\bar{\tau}}_{s}-\beta\left(\vec{v}_{g}-\vec{v}_{s}\right)+\alpha_{s} \rho_{s} \vec{g} \cos \theta-\dot{m}_{s g} \vec{v}_{s g}+\vec{R}_{g s}
\end{aligned}
$$

where the terms in the left sides of eqs 4 and 5 represent the momentum increase and transfer, respectively, while the terms in the right sides represent the contribution of pressure force, stress tensor, solid-gas momentum exchange with drag coefficient $\beta$, gravity force with inclination angle $\theta$, momentum transfer due to evaporation and interphase momentum transfer due to the pyrolysis reaction (given by $\vec{R}=\dot{m} \vec{v}$ ), respectively. In order to take into consideration the high turbulence arising from the flow fluctuation (gas vortices), especially near the separator, the above momentum equations have been coupled with the standard two equations $k-\varepsilon$ model with wall function as proposed by Launder and Spalding ${ }^{31}$. This model is widely used and reported to provide reasonable agreement with experimental measurements in various forms of intermediate to dilute flow systems such as circulating fluidized beds and pneumatic conveyers. ${ }^{32,33,34}$ Compared to other optional models available in Fluent simulation platform, the $k-\varepsilon$ model has also been found to be computationally stable and robust for the scale of problem considered here.

The particulate phase (biomass) was treated as continuum, therefore, the solid stress is related to the velocity fluctuations expressed in terms of the granular temperature as follows:

$$
\frac{3}{2}\left(\frac{\partial}{\partial t}\left(\alpha_{s} \rho_{s} \Theta_{s}\right)+\nabla\left(\alpha_{s} \rho_{s} \vec{v}_{s} \Theta_{s}\right)\right)=\left(-P_{S} \overline{\bar{I}}+\overline{\bar{\tau}}_{s}\right): \nabla \vec{v}_{s}-\nabla\left(k_{\Theta_{s}} \nabla \Theta_{s}\right)-\gamma_{\Theta_{s}}+\phi_{g s}
$$

where $\Theta_{s}$ is the granular temperature. The terms in the left side represent the rate of increase and transfer of granular energy, while the terms in the right side represent the energy generation, diffusive granular energy flux (with coefficient $k_{\Theta_{S}}$ ), energy collisional dissipation and energy exchange between the solid and gas, respectively. The main constitutive equations for the above model (eqs 1-6) are given in the support information (Table S1). Note that the inter-particle friction has been ignored in the solid phase stress model due to the low range of solid concentration considered. 


\subsection{Energy and species transport model}

The energy and chemical species transport models have been solved based on the following main assumptions:

i. The pyrolysis gas is treated as an ideal gas mixture consisting of various species.

ii. The biomass particle retains its original size and shape during pyrolysis.

iii. The biomass particle density changes as a result of release of gases.

iv. The biomass particle has negligible internal thermal resistance, hence uniform temperature applies.

v. The heat transfer by radiation inside the reactor is negligible due to the temperature falling below the level of effective radiative heat. ${ }^{35,36}$

The energy balance equations for the solid and gas phases are given by:

$$
\begin{aligned}
& \frac{\partial\left(\alpha_{g} \rho_{g} h_{g}\right)}{\partial t}+\nabla\left(\alpha_{g} \rho_{g} \vec{v}_{g} h_{g}\right) \\
& =\alpha_{g} \frac{\partial P_{g}}{\partial t}+\overline{\bar{\tau}}_{g}: \nabla \vec{v}_{g}-\nabla \vec{q}_{g}+S_{g}+a_{g s} h_{c, g s}\left(T_{g}-T_{s}\right)-\dot{m}_{s g} h_{s g} \\
& \begin{aligned}
\frac{\partial\left(\alpha_{s} \rho_{s} h_{s}\right)}{\partial t}+ & \nabla\left(\alpha_{s} \rho_{s} \vec{v}_{s} h_{s}\right) \\
= & \alpha_{s} \frac{\partial P_{s}}{\partial t}+\overline{\bar{\tau}}_{s}: \nabla \vec{u}_{s}-\nabla \vec{q}_{s}+S_{s}+a_{s g} h_{c, s g}\left(T_{s}-T_{g}\right)+\dot{m}_{s g} h_{s g}
\end{aligned}
\end{aligned}
$$

where $\vec{q}$ is the heat flux, $S$ is source term for enthalpy due to reaction, $h_{c}$ is the heat transfer coefficient between the gas and solid phases, $a$ is the interfacial area, and $h$ is the interphase enthalpy due to evaporation.

The solid-gas heat transfer coefficient is given by:

$$
h_{c, s g}=\frac{k_{g} N u_{s}}{d_{s}}
$$

where $k_{g}$ is the thermal conductivity of the gas phase, $d_{s}$ is the biomass particle diameter and $N u_{s}$ is the Nusselt number given by Gunn's correlation as follows: ${ }^{37}$

$$
N u_{s}=\left(7-10 \alpha_{g}+5 \alpha_{g}^{2}\right)\left(1+0.7 \operatorname{Re}_{s}^{0.2} \operatorname{Pr}^{1 / 3}\right)+\left(1.33-2.4 \alpha_{g}+1.2 \alpha_{g}^{2}\right) \operatorname{Re}_{s}^{0.7} \operatorname{Pr}^{1 / 3}
$$

where $R e_{s}$ is the particle Reynolds number and $\operatorname{Pr}$ is the prandtl number.

The transfer of the chemical species in the gas phase is calculated by the following equation:

$$
\frac{\partial\left(\alpha_{g} \rho_{g} Y_{i, g}\right)}{\partial t}+\nabla\left(\alpha_{g} \rho_{g} \vec{u}_{g} Y_{i, g}\right)=-\nabla \cdot \alpha_{g} \vec{J}_{i, g}-\dot{m}_{i, s g}+R_{i}
$$


where $Y_{i, g}$ is the mass fraction of gas species, $\vec{J}_{i, g}$ is the diffusion flux, $\dot{m}_{i, s g}$ is the mass transfer rate from the biomass to the gas phase due to drying and $R_{i}$ is the mass transfer rate due to heterogeneous reactions.

\subsection{Drying and pyrolysis model}

In deriving the biomass drying and pyrolysis models a number of assumptions have been made as follows:

i. The biomass releases a pyrolysis gas mainly consisting of condensable hydrocarbons (bio-oi), non-condensable gas consisting of $\mathrm{H}_{2}, \mathrm{CH}_{4}, \mathrm{CO}$ and $\mathrm{CO}_{2}$ in addition to $\mathrm{H}_{2} \mathrm{O}$ vapor and char.

ii. The pyrolysis reaction is represented by a single chemical reaction with the reaction rate given by the Arrhenius equation.

iii. The homogenous reaction (gas-gas) (i.e. thermal cracking, reforming, combustion etc.) are negligible due to the low reactor temperature, limited oxygen and short gas residence time.

iv. The heterogeneous reactions between the pyrolysis gas and char are negligible due the fast separation of the phases.

The following equation was used for the mass transfer of moisture during drying ${ }^{38}$

$$
\dot{m}_{s g}=k_{c} \times \alpha_{m} \rho_{m} \frac{\left(T_{v a p}-T_{s a t}\right)}{T_{s a t}}
$$

where $\dot{m}_{s g}$ is the mass transfer rate of water from the biomass to the gas phase, $k_{c}$ is the mass transfer coefficient, $\alpha_{m}$ and $\rho_{m}$ represent the volume fraction and density of the water content in the biomass, $T_{v a p}$ and $T_{\text {sat }}$ are the vapour phase temperature and $T_{\text {sat }}$ is the saturation temperature $\left(100^{\circ} \mathrm{C}\right)$, respectively. The values of the transfer coefficient $k_{c}$, which is treated as a time relaxation parameter, was fine-tuned and the value of $0.1 \mathrm{~s}^{-1}$ was found to provide satisfactory results.

The pyrolysis reaction was represented by a single-step reaction, as mentioned in the assumptions, as follows:

$$
\text { Biomass } \rightarrow \alpha_{1} \text { char }+\alpha_{2} \mathrm{Oil}+\alpha_{3} \mathrm{H}_{2} \mathrm{O}+\alpha_{4} \mathrm{H}_{2}+\alpha_{5} \mathrm{CO}+\alpha_{6} \mathrm{CO}_{2}+\alpha_{7} \mathrm{CH}_{4}
$$




\section{Solution procedure and boundary conditions}

\subsection{Simulation domain meshing}

The geometry of the simulation domain was discretised into finite subdomains or elements. A total number of 162377 elements was generated using tetrahedral (unstructured) meshing method. The regions near the conical deflector and the lower section of the reactor, where the concentrated solar irradiation is focused, were discretised with fine cells (minimum and maximum element face sizes of $0.5 \mathrm{~cm}$ and $1.0 \mathrm{~cm}$, respectively). These are the regions where steep variation in the hydrodynamics and temperature are expected to take place. The rest of the simulation domain was discretized using relatively coarse elements (minimum and maximum element face size of 1.0 and $5.0 \mathrm{~cm}$, respectively). This meshing scheme has been defined after analysing the solution sensitivity to various meshing schemes (not shown here) and has been found to considerably reduce the computational time without jeopardizing the solution accuracy. 


\subsection{Boundary conditions}

The walls of the reactor and the conical separator were treated in the model as stationary boundaries with no-slip conditions (zero velocity) for the gas phase. The solid phase was modelled with wall shear based on the following boundary condition: ${ }^{40}$

$$
\begin{aligned}
& u_{s}=-\frac{6 \mu_{s} \alpha_{s, \max }}{\left(3 \Theta_{s}\right)^{1 / 2} \pi \varphi \rho_{s} \alpha_{s} g_{0, s s}} \frac{\delta u_{s}}{\delta n} \\
& \Theta_{s}=-\frac{k_{s} \Theta_{s}}{\gamma_{w}} \frac{\delta \Theta_{s}}{\delta n}+\frac{\sqrt{3} \pi \varphi \rho_{s} \alpha_{s} u_{s}^{2} g_{0, s s} \Theta_{s}^{3 / 2}}{6 \alpha_{s, \max } \gamma_{w}}
\end{aligned}
$$

where $\varphi$ is the specularity coefficient and $e_{\text {wall }}$ is the particle-wall restitution coefficient.

The reactor wall was assumed to be of zero thickness to simplify the problem and avoid significant increase in the number of computational cells. For this condition, the wall thermal resistance is zero, i.e. no wall conduction applied. Along the length of $3.7 \mathrm{~m}$ from the reactor entrance (solar heated length) a constant heat flux on the lower wall boundaray was specified in the model with the following coordinates:

$$
q^{\prime \prime}=12.55 \mathrm{kWm}^{-2} \quad \text { at }-D / 2 \leq r \leq 0,-90^{\circ} \leq \alpha \leq 90 \text { and } 0 \leq L \leq 3.7 \mathrm{~m}
$$

where $q^{\prime \prime}$ is the concentrated solar irradiation (heat flux per reciving area), $L$ is the total reactor length, $\alpha$ is the solar acceptance angle and $D=\emptyset d_{3}$ is the reactor diameter, as shown earlier in Figure 2. The upper part of the reactor is specified as adiabatic boundary, i.e. zero heat flux condition, with the following coordinates:

$$
q^{\prime \prime}=0 \mathrm{kWm}^{-2} \quad \text { at } 0 \leq r \leq D / 2,-90 \leq \alpha \leq 90^{\circ} \text { and } 0 \leq L \leq 3.7 \mathrm{~m}
$$

The boundary at the nitrogen inlet was set to a fixed mass flow rate $3.9 \mathrm{~g} / \mathrm{s}$ and a temperature of $400{ }^{\circ} \mathrm{C}$ (giving an inlet gas velocity of $2.27 \mathrm{~m} \mathrm{~s}^{-1}$ ). At the biomass feeding boundary, the condition was set to a fixed solid flow rate of $1.0 \mathrm{~g} / \mathrm{s}$ and temperature of $30^{\circ} \mathrm{C}$. At the gas discharge pipe, the outlet was fixed to atmospheric pressure.

\section{Results and discussion}

\subsection{Hydrodynamics and temperature distribution}

The solid-gas separation method applied in this study is relatively new and its application in chemical reactors has only been reported in few recent studies by Huard et al. ${ }^{27}$ and Yu et al. ${ }^{28-}$ 29. In these studies, it was shown that the separation device can achieve more than $99 \%$ separation efficiency in downer reactors. The separation is caused by the abrupt pressure drop 
Figure 3 shows the solid (biomass) distribution in the reactor at steady flow condition. The flow appears to be fully developed after a short distance from the entrance. The solid (biomass) forms a highly dilute suspension over a relatively denser layer near the bottom wall. The upper part of the reactor is predominantly occupied by the gas phase. This is a classic feature of dilute or rapid solid flow in horizontal or slightly inclined pipes and is commonly referred to in pneumatic conveying literature as a strand flow. ${ }^{41,42}$ In the region around the separator, it is evident that the main solid flow is deflected away from the tip of the gas discharge pipe to pass the deflector through the lower gap. There is an argument that in extremely low solid concentration, particle trajectory crossing become significant ${ }^{43}$. In this case, it is suggested to modify the particle phase momentum, or alternatively, use Eulerian-Lagrangian method, which facilitate calculating the trajectory of the discrete particles. However, both options are computationally expensive for the problem under consideration, besides, the former option is yet to be proven in its full form. In the model used here, it is assumed that in the regions of extremely low solid concentration, the random particle velocity is high, and in the absence or limited collisions, the particle motion is governed by streaming mechanism due to high relative velocity between the gas and solid phases. At the relatively denser layer, it is expected that instantaneous binary collisions become important and the motion fall under the influence of kinetic-collisional stress and energy dissipation. It is therefore, reasonable here to adopt unified closure equations derived from the kinetic theory of granular flow (KTGF) coupled with the momentum and "granular temperature" to capture the flow filed in both regimes. 

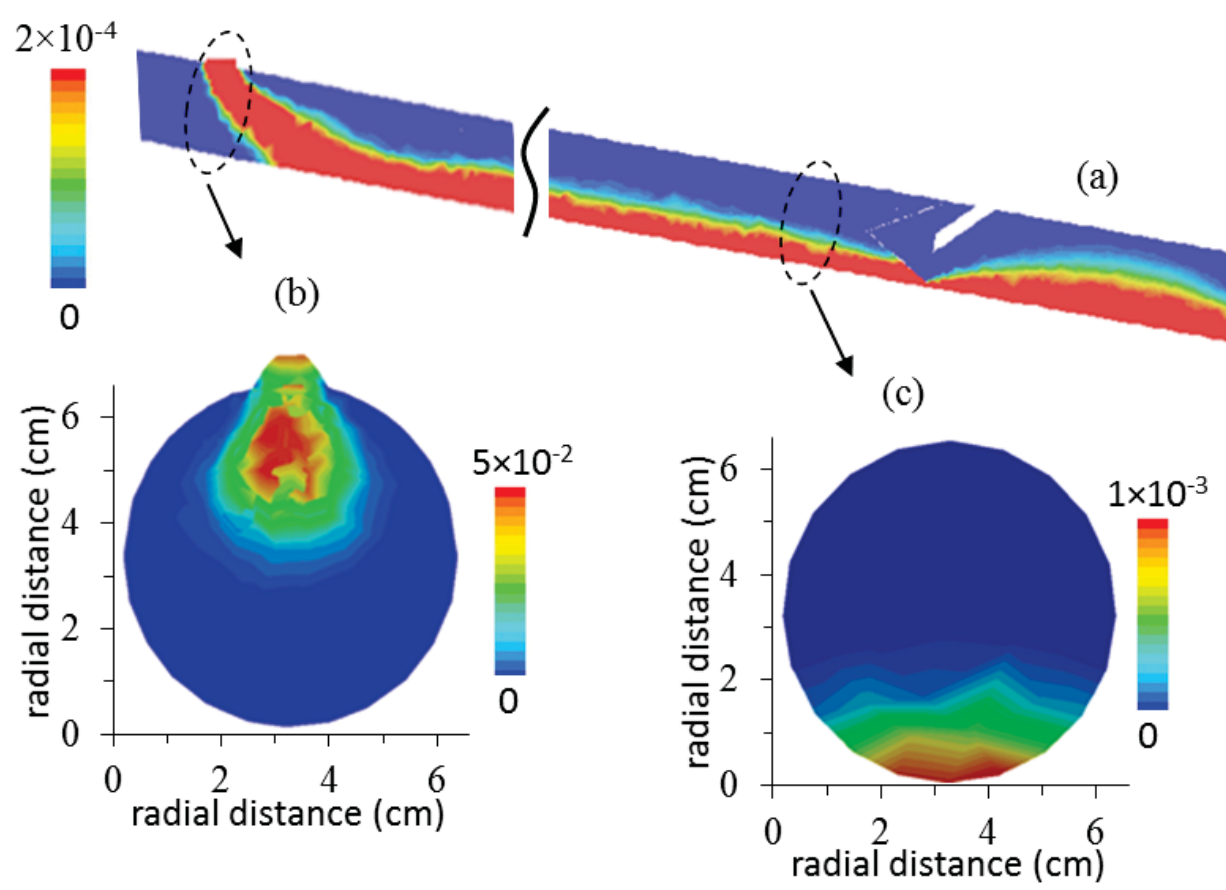

Figure 3. Solid (biomass) concentration (a) axial cross-section concentration profile over the entire simulation domain (concentration restricted to $2 \times 10^{-4}$ to allow better visualization) (b) and (c) radial cross-section contour at the reactor entrance and $3.5 \mathrm{~m}$ from the entrance, respectively.

The gas velocity shown in Figure 4 reveals further details on the flow hydrodynamics and the solid separation mechanism. The main feature observed here is that the small gap between the conical deflector and reactor wall creates significant pressure drop which gives the gas a very high velocity resembling the behaviour observed in swirling vane and cyclone devices. The gas velocity profiles appear to be reasonably uniform and almost symmetric in most parts, except at the far top as clear in Figure 4d. However, in the region beyond the separator, as shown in Figure $4 \mathrm{~d}$, the gas velocity vectors indicate a reverse flow towards the lower wall before the gas discharges through the exit pipe. The velocity is at highest value in the gas passage gap and in the low pressure region around the tip of the gas discharge pipe. The gas dis-engagement (separation form the main stream flow) takes place within a short distance beyond the separation cone rim. This is very similar to the behaviour observed in a downer reactor applying the same separation mechanism, where it was shown that the gas dis-engagement distance falls within the range of $2.5-6 \mathrm{~cm}$ from the separation cone rim. ${ }^{28}$ 

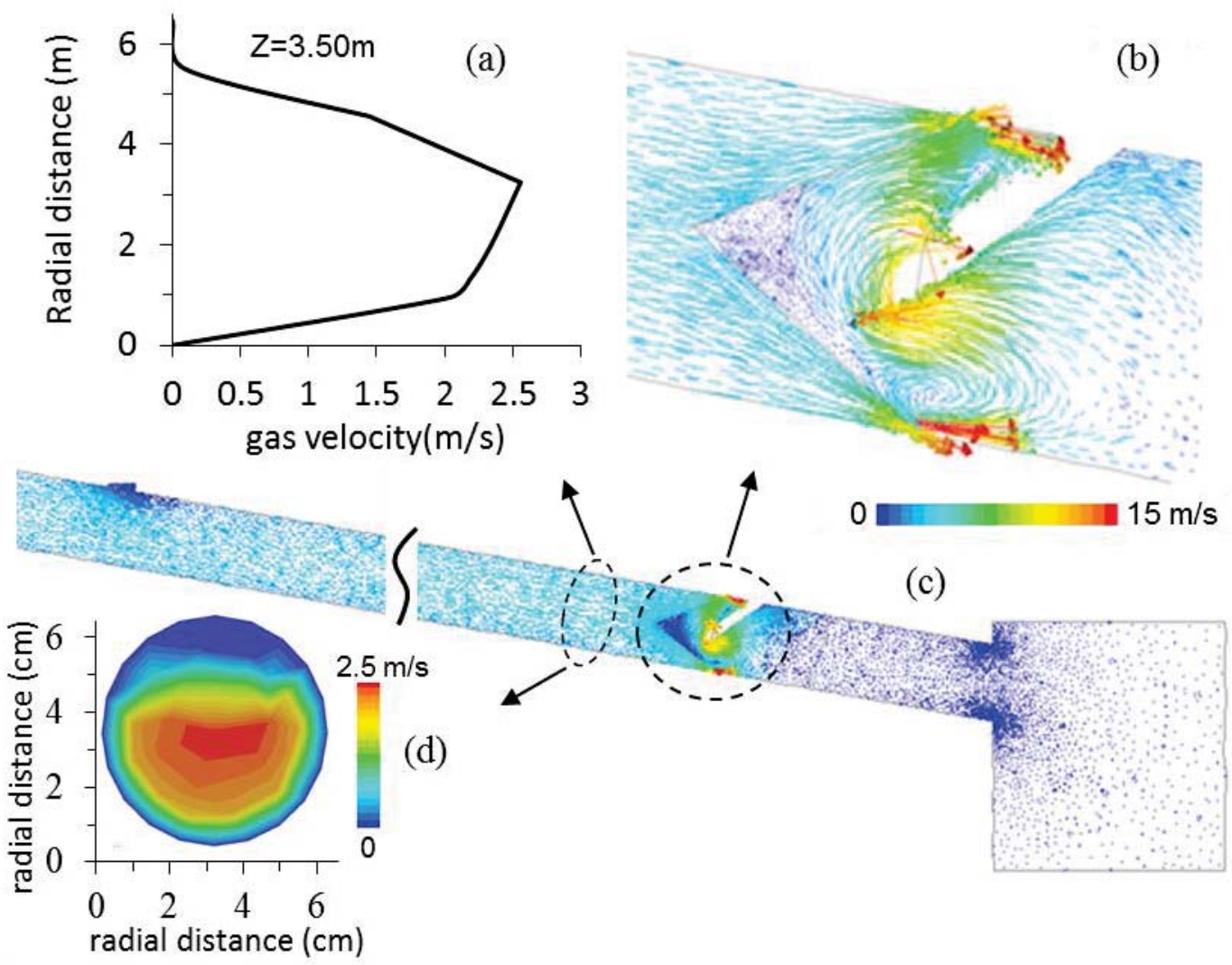

Figure 4. Gas velocity distribution (a) Radial velocity profile at $3.5 \mathrm{~m}$ from the entrance (b) radial cross-section of velocity contour at $3.5 \mathrm{~m}$ from the entrance (c) axial cross-section vectors over the entire simulation domain (d) axial cross-section of velocity vectors around the separator zone.

The performance of a pyrolysis reactor strongly depend on the heating rate and temperature distribution. Because of the asymmetric heating and non-uniformity in the solid flow structure, as shown in Figure 3, it is important to discuss the impact of these on the overall reactor thermal performance. Figures 5a and 5b show that the average temperature of the solid and gas phases within the fully developed flow region is above $440{ }^{\circ} \mathrm{C}$, except at the start and end, which are under the influence of entrance and exit effects. This indicates that the supplied heat is sufficient to maintain the reactor at the desired range of temperatures while satisfying the highly endothermic pyrolysis reaction. Because the solid is introduced at a cold condition (27 ${ }^{\circ} \mathrm{C}$ ) it takes longer to attain the same temperature of the gas, i.e. thermal equilibrium. The results show that the distance to reach thermal equilibrium, often called the thermal entrance length, is around $1.0 \mathrm{~m}$ from the biomass feed point. It is highly desirable to have this length as short as possible in order to simplify the reactor design, satisfy the requirement of short gas residence time and minimize the contact between the bio-char and gas. Figures $5 \mathrm{c}$ and $5 \mathrm{~d}$ show 
that the temperature near the dense lower wall is consistently close to $650{ }^{\circ} \mathrm{C}$. In the upper dilute layer, which is predominantly occupied by the gas, the temperature falls within the range of $420-450{ }^{\circ} \mathrm{C}$.
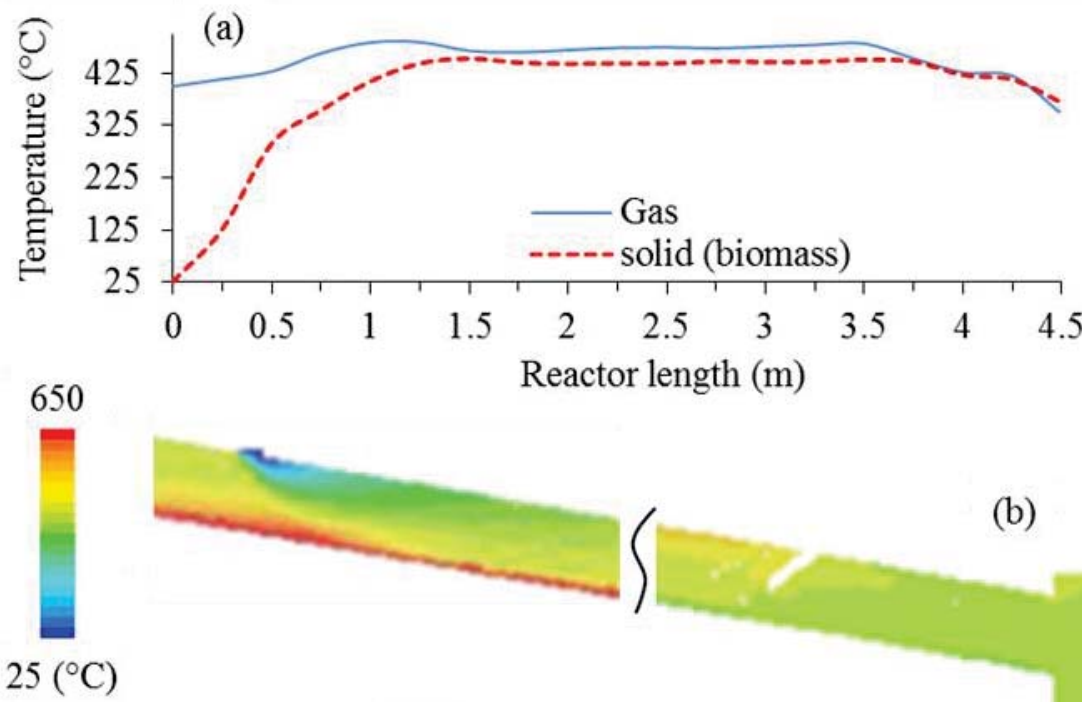

(b)

(c)

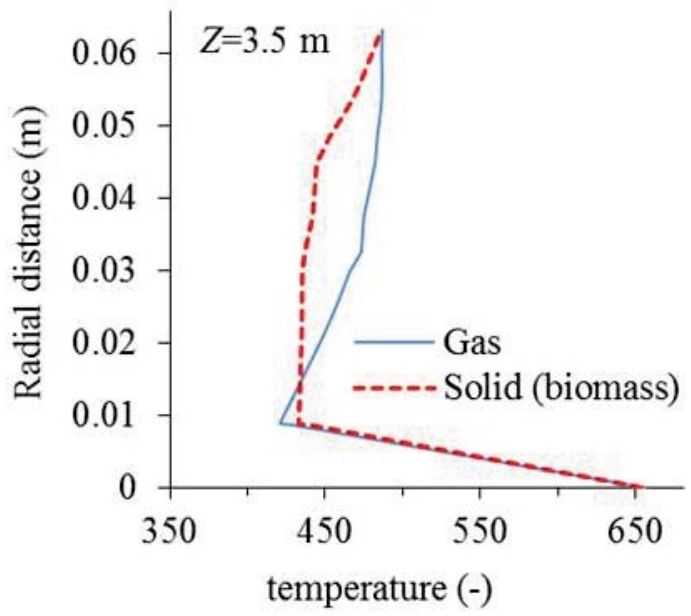

(d)

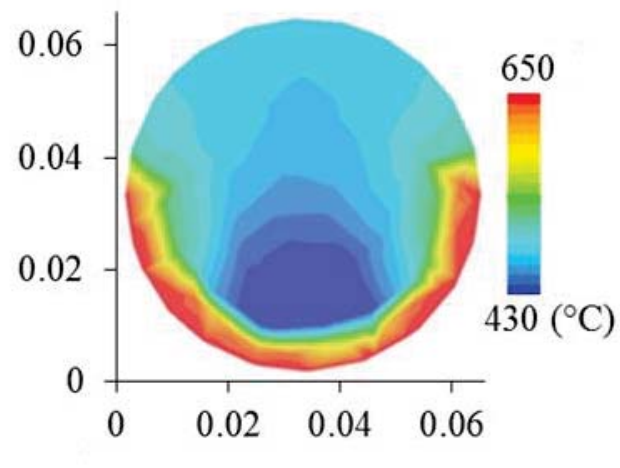

Figure 5. Temperature distribution of the solid and gas phases (a) average axial temperature profiles of the gas and solid phases (b) contour plot of the gas axial temperature distribution over the entire simulation domain (c) radial temperature profiles of the gas and solid phases at $3.5 \mathrm{~m}$ from the entrance $(\mathrm{d})$ contour plot of the gas temperature distribution at $3.5 \mathrm{~m}$ from the entrance.

In summary, the distinct flow characterises and thermal behaviour shown here are of particular interest in biomass pyrolysis because of three main advantages:

i. The proposed reactor offers an excellent environment for rapid release of volatiles (pyrolysis gas) from the relatively slow moving biomass layer concentrated near the 


\subsection{Residence time distribution}

In a fast pyrolysis reaction, it is important to control the gas residence time in order to maximize the bio-oil yield. In this analysis, the gas residence time distribution (RTD) was obtained by a numerical procedure based on tracer tracking method. ${ }^{44,45}$ This was simulated by injecting 100 massless particles (tracers) at the biomass feeding point. The tracers, which are assumed to travel at the same speed as the gas phase, were then monitored at the tip of the gas exit pipe to obtain the gas (RTD). Figure 6 shows the pathlines of the individual tracers and the corresponding gas residence time distribution (RTD). The color of the pathlines reflects the variations in residence time. The reverse in pathlines appearing beyond the separator is in good agreement with the velocity vectors shown earlier in Figure 4d. The RTD curve in Figure 6a indicates a narrow time distribution with peak at $1.55 \mathrm{~s}$. This is well within the recommended range for high bio-oil yield. As for the particle phase, the residence time is expected to be higher and, most importantly, sufficient enough to ensure high devolatilization rate. 


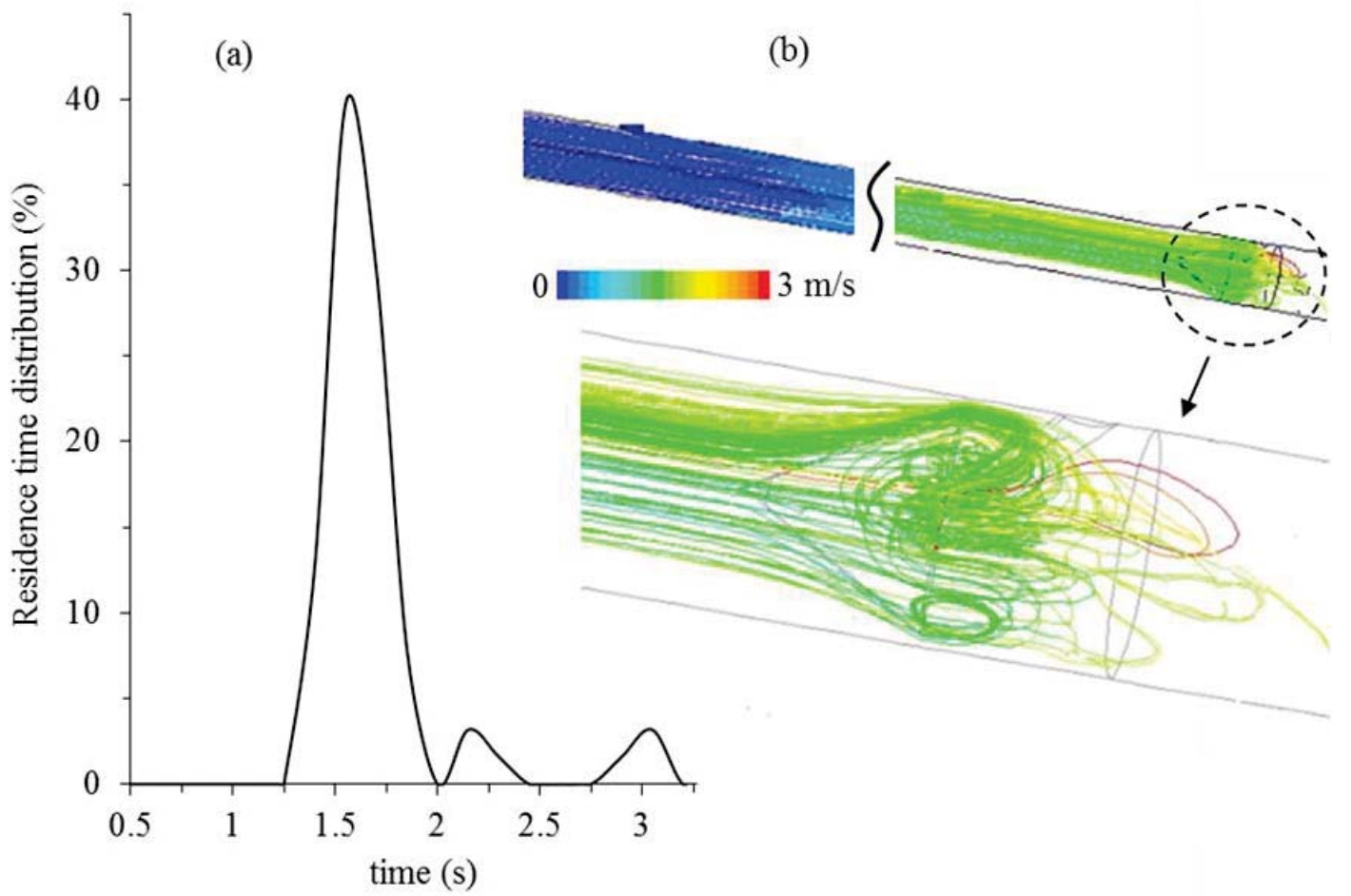

Figure 6. Gas residence time in the pyrolysis reactor (a) residence time distribution (b) Pathlines of tracers as representation of the gas phase flow filed at steady condition.

\subsection{Solid-gas separation and devolatilization efficiencies}

The separation efficiency is defined as the ratio of solid mass flow rate at the receiving tank to the total solid feeding rate. This is given by:

$$
\eta_{\text {sep }}=\frac{\dot{m}_{s, \text { in }}-\dot{m}_{s, \text { out }}}{\dot{m}_{s, \text { in }}}
$$

where $\dot{m}_{s, \text { out }}$ is the rate of solid leaving with the gas (entrained) through the separator pipe and $\dot{m}_{s, i n}$ is the rate of solid feeding to the reactor $\left(\dot{m}_{s, i n}\right)$. Figure 7 shows the percentage separation efficiency as function of time (from the start of the biomass feeding up to the time reaching steady state). During the initial stage, no entrainment takes place due to the delay in the solid flow reaching the gas exit pipe (developing flow), hence, the gas detected at this time is $100 \%$ clean. After around $2 \mathrm{~s}$, the record of entrainment starts to increase while the multiphase flow stabilizes and eventually reaches steady separation efficiency of around $99.99 \%$ at 3 s. This is in good agreement with the range of efficiencies reported in previous studies using the same separation mechanism in a downer reactor. ${ }^{27-29}$ This is also close to the range of separation that would be achieved in a conventional cyclone for the same particle size. However, this separation mechanism has the added advantages as follows:

(a) Reduced risk of catalytic cracking of the pyrolysis gas due to in-situ fast separation 
from the bio-char, as noted earlier.

(b) High gas-solid separation efficiency, independent of the gas flow rate, as reported in previous experimental and numerical investigations. ${ }^{27,28}$

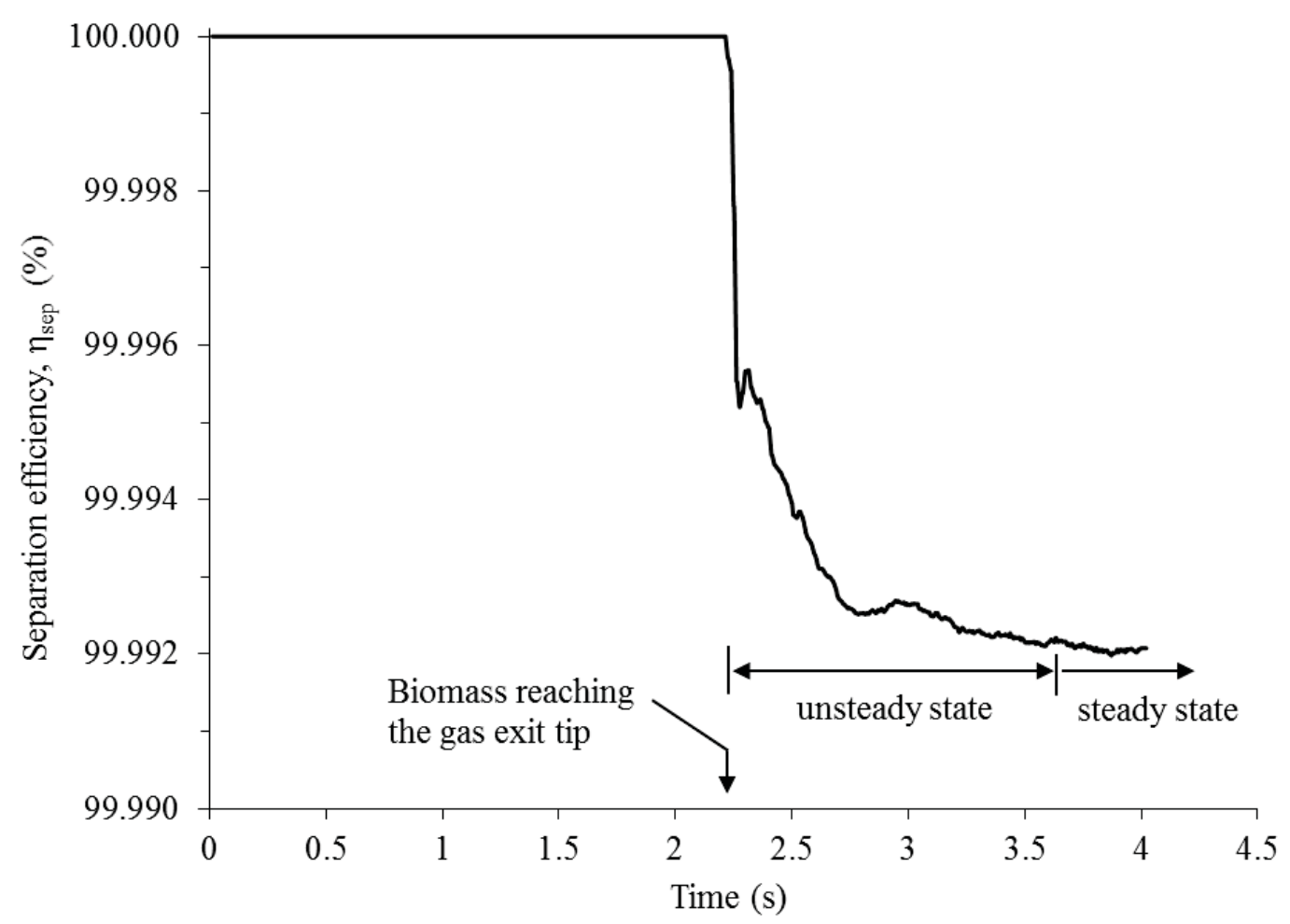

Figure 7. Temporal evolution of the solid separation efficiency measured at the tip of the gas exit pipe. Zero time is at the start of biomass feeding to the reactor.

The devolatilization efficiency is defined as the ratio of mass flow of volatiles (pyrolysis gas excluding water vapour) removed from the biomass $\left(\right.$ vol $\left._{\text {removed }}\right)$ to the mass existing in the fresh feed biomass $\left(\right.$ vol $\left._{\text {in }}\right)$ as follows:

$$
\eta_{d}=\frac{\text { vol }_{\text {removed }}}{\text { vol }_{\text {in }}}
$$

Figure 8 shows the percentage devolatilization efficiency and the corresponding mass fraction of water vapour and bio-oil in the total gas released as function of the reactor length. The variation of the temperature is included to show the relation between the release of volatiles and temperature. The maximum devolatilization efficiency achieved is $62 \%$. This implies that the remaining volatiles (38\% of the original mass of volatiles), along with the fixed carbon and ash, will be collected in the receiving tank as char. As expected, the moisture appear to be removed from the biomass as soon as the temperature reaches $100{ }^{\circ} \mathrm{C}$. As the temperature then 
increases along the reactor length, the bio-oil yield increases. It is interesting to note that, within the thermally developed section the reactor, the devolatilization linearly increases with the length. The temperature at the start of devolatilization coincides with the average biomass temperature of around $225{ }^{\circ} \mathrm{C}$ (see the inset in Fig. 8). This agrees well with the reported literature which suggests that the start of hemicellulose decomposition occurs at around the same temperature. ${ }^{46}$

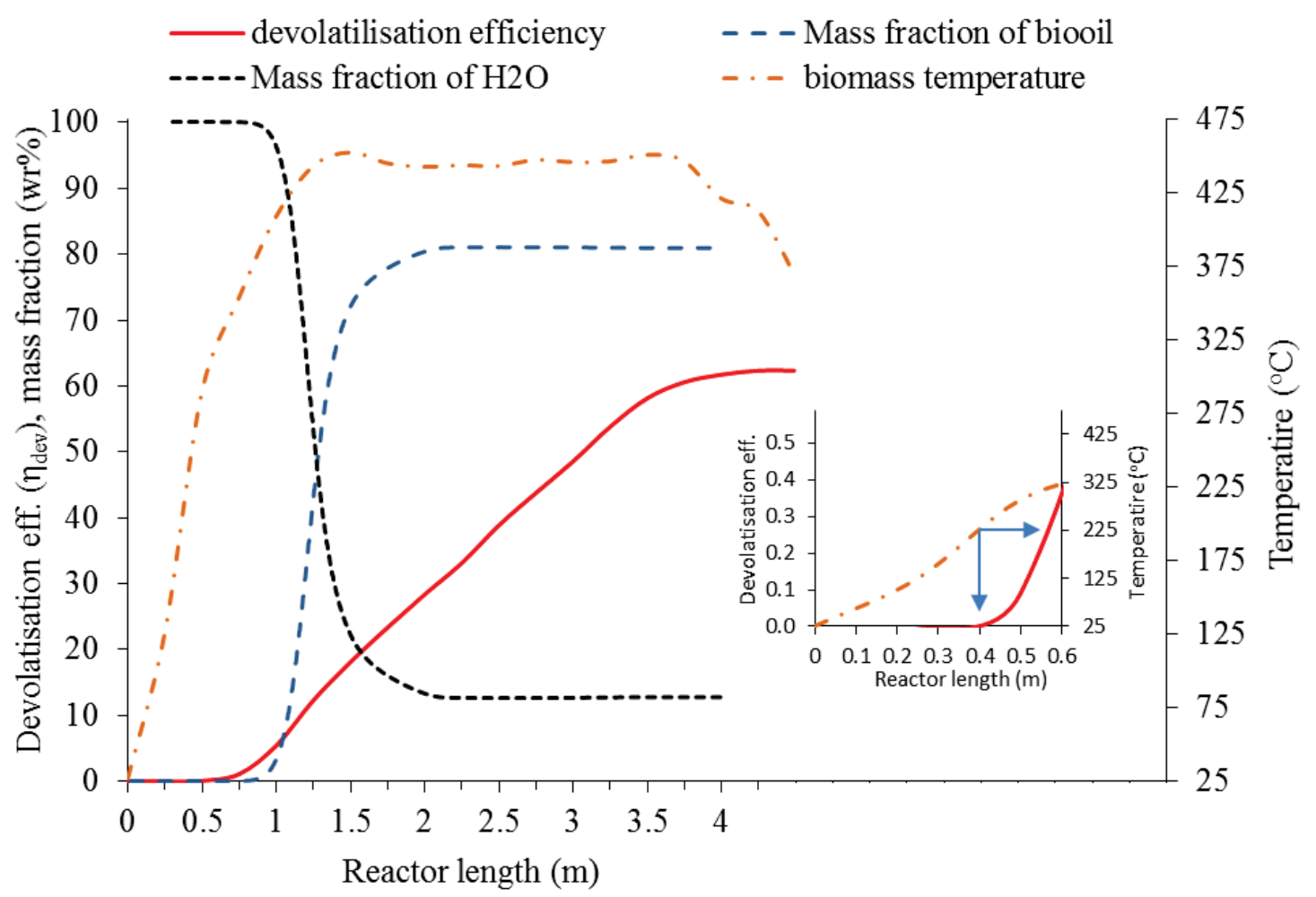

Figure 8. The variation of devolatilization efficiency, mass fraction of the bio-oil and water in the total gas released and the corresponding biomass temperature along the reactor length. The inset, which is in different axes scale, shows the temperature at the onset of devolatilization.

\subsection{Product composition and comparison with literature data}

In this section the predicted product composition (bio-oil, non-condensable gas and char) is compared with selected literature data produced in various types of pyrolysis reactors (see Table S2 in the supporting information for details of the reactors types and operating condition). The mass flow of the pyrolysis gas was recorded at the tip of the gas exit pipe at steady condition. Figure 9a shows the predicted bio-oil yield in comparison with the literature data produced in partially and fully solar heated pyrolysis reactors. ${ }^{17,47,48}$ While there is clear agreement between this study and the data of Joardder et al. ${ }^{48}$, discrepancies are expected due to the differences in reactors geometries, biomass type, gas residence time and temperature. 
Particularly, in the study by Morales et al. ${ }^{17}$, the bio-oil yield appear to be considerably enhanced by the presence of photochemical effect caused by the solar radiation penetrating into the biomass directly through the reactor glass wall. It is also important to note the major difference in biomass residence time in fixed beds and flow reactors.

Figure 9b shows the composition of the overall product (bio-oil, non-condensable gas and char) in comparison with wider literature data obtained in various conventionally heated reactors. Again, understandably, there is noticeable variations in the product composition due to the differences in reactors and operating conditions used, nevertheless, the comparison allows drawing conclusion on the competitiveness of the proposed solar reactor. The high bio-oil yield and low Char content noticed in the data of Authier et al. ${ }^{49}$ and Boateng et al. ${ }^{30}$ suggest an enhanced devolatilization, however, there seem to be excessive secondary reactions leading to breakdown of heavy hydrocarbons to light gases as indicated by the relatively high noncondensable gas fraction.

Figure 9c shows the composition of the non-condensable gas predicted in this study in comparison with the experimental literature data obtained in various types of conventionally heated reactors. The predictions of this study show low $\mathrm{CO}$, high $\mathrm{CO}_{2}$ and almost nil $\mathrm{H}_{2}$. In reality, the $\mathrm{CO}$ and $\mathrm{CO}_{2}$ are usually higher due to the excessive contact between the char and the pyrolysis gas, which in turn lead to catalytic effects through the following reactions:

i. Boudouard reaction: consuming $\mathrm{CO}_{2}$ and producing $\mathrm{CO}\left(\mathrm{C}+\mathrm{CO}_{2} \rightarrow 2 \mathrm{CO}\right)$

ii. Shift reaction: giving more $\mathrm{CO}$ and $\mathrm{H}_{2}\left(\mathrm{C}+\mathrm{H}_{2} \mathrm{O} \rightarrow \mathrm{H}_{2}+\mathrm{CO}\right)$

In this study, the model justifiably ignores these reactions due the in-situ and quick separation of the pyrolysis gas from the char and because of the noticeable separation of the solid and gas phases, i.e. dilute suspension moving over a relatively dense layer (see Figure 3a). These factors typically result in increasing $\mathrm{CO}_{2}$ and lowering $\mathrm{CO}$ and $\mathrm{H}_{2}$, which is consistent with this study predictions. 

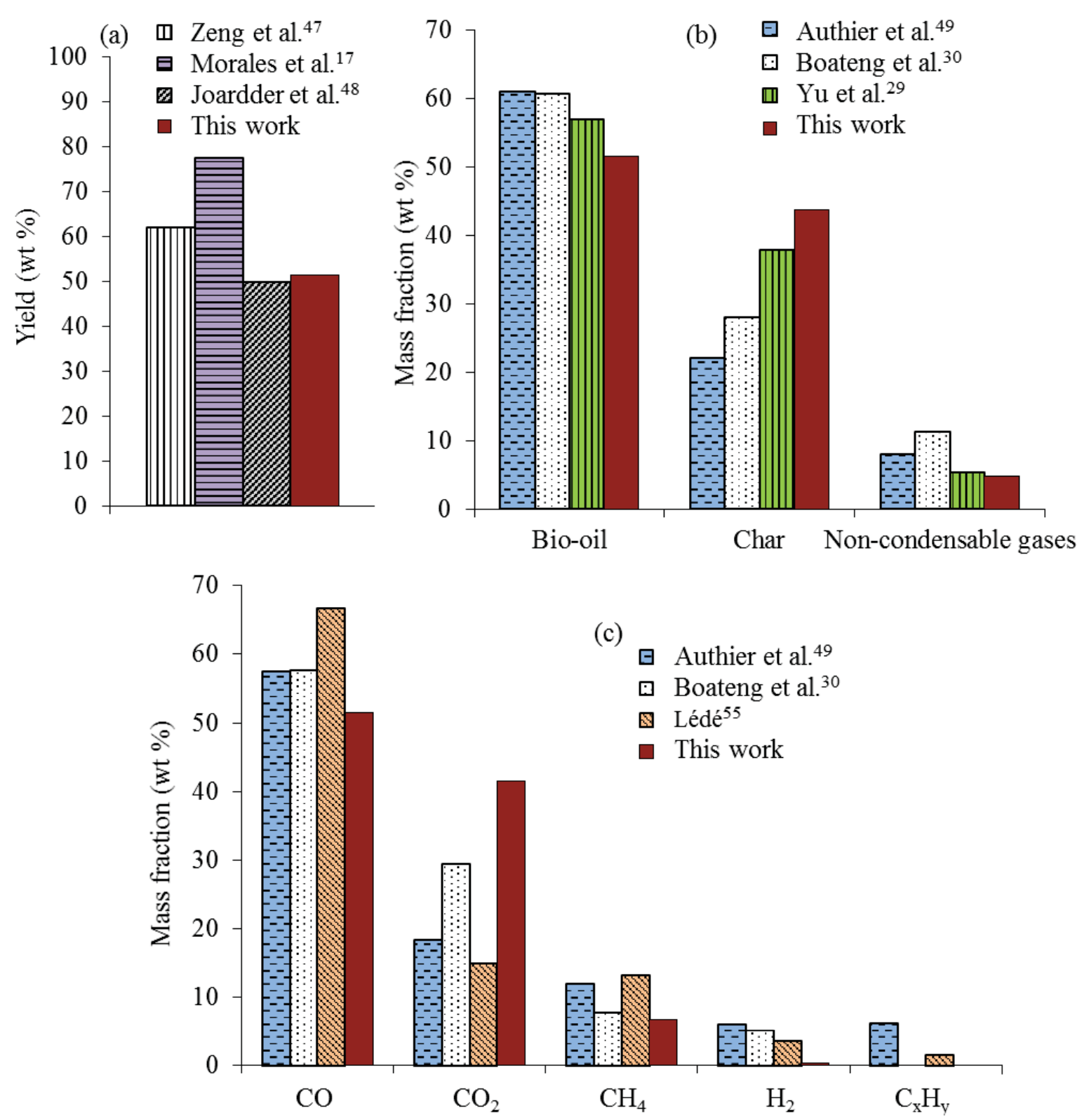

Figure 9. Products composition in comparison with the literature data (a) Bio-oil yield compared to literature data obtained in solar reactors (b) mass composition of the overall product compared to the wider literature data (c) mass composition of the non-condensable gas in comparison to the literature data. Details of reactors and operating conditions are given in the supporting information (Table S2).

\subsection{Energy conversion and reduction in GHG emission}

Finally, having now demonstrated the potential of the proposed reactor in producing high quality fuel, it is of interest to evaluate the performance in terms of greenhouse gas (GHG) emissions, overall energy conversion efficiency $\left(\eta_{\text {all }}\right)$ and solar-chemical conversion efficiency $\left(\eta_{\text {sol-chem }}\right)$. The efficiencies were defined in terms of energy ratios as follows: 


$$
\begin{gathered}
\eta_{\text {all }}=\frac{\sum \dot{m}_{\text {pro }} \times H H V_{\text {pro }}}{\dot{n}_{\text {feed }} \times H H V_{\text {feed }}+Q_{\text {solar }}} \\
\eta_{\text {sol-chem }}=\frac{\sum \dot{m}_{\text {pro }} H_{\text {pro }}(T)-\sum \dot{n}_{\text {feed }} H_{\text {feed }}(T)}{Q_{\text {solar }}}
\end{gathered}
$$

where $\dot{m}_{\text {pro }}$ and $H H V_{\text {pro }}$ are the mass flow and the high heating value of each component in the products (bio-oil, non-condensable gas and char), $\dot{n}_{f e e d}$ and $H H V_{\text {feed }}$ are the mass flow of biomass and its high heating value, respectively, $H_{\text {pro }}$ and $H_{\text {feed }}$ are the enthalpies of each component in the product and feed respectively, and $Q_{\text {solar }}$ is the solar heat flux concentrated at the reactor wall. The enthalpy at any temperature $T$ is given by:

$$
H(T)=\Delta H_{f, 298}^{0}+\int_{298}^{T} C_{p} d T
$$

where $\Delta H_{f, 298}^{0}$ is the heat of formation at the reference temperature $298 \mathrm{~K}$. For the noncondensable gases, this was obtained from the open literature, while for the biomass, bio-oil and char this was obtained from the following formula: ${ }^{50}$

$$
\Delta H_{f, 298}^{0}=H H V-(0.327 C+1.417 H+0.093 S+0.158 M)
$$

where $C, H, S$ and $M$ represent the percentage mass fractions of carbon, hydrogen, sulphur and moisture contents in the fuel respectively.

The $H H V$ was calculated using a unified correlation for solid and liquid fuels as follows: ${ }^{51}$

$H H V=0.3491 C+1.1783 H+0.1005 S-0.1034 O-0.0151 N-0.0211 A$

where $O, N$ and $A$ represent percentage mass fraction of oxygen, nitrogen and ash on dry basis respectively. Note that, in eqs 25 and 26, the $H H V$ values are in $\mathrm{MJ} / \mathrm{kg}$ and the fractions of the elements for biomass are that of the ultimate analysis given in Table 1. For the bio-oil, these fractions were obtained from the experimental data reported in Jahirul et al. ${ }^{26}$. The contribution of the carrier gas (nitrogen) in the above analysis has been ignored due to its inert nature and its almost constant temperature between the inlet and exit.

The calculated overall and solar-chemical conversion efficiencies ( $\eta_{\text {all }}$ and $\eta_{\text {sol-chem }}$, respectively) are compared with the data reported for gasification, pyrolysis and methanol decomposition in Table 5 (details of the reactors and operating conditions are given in the supporting information Table S2). There is a general agreement in the literature that biomass conversion efficiency in terms of energy ratio falls within the range of $60-75 \% .^{52}$, which is 
within the range predicted here $\left(\eta_{\text {all }}=67.8 \%\right)$. The experimental work of Michael Krüsi ${ }^{53}$ show a considerably low overall efficiency of $21 \%$. The authors attributed this to the considerable heat losses experienced during the experiment.

Table 5. Overall and solar-chemical conversion efficiencies. Details of the type of reactors and operating conditions used in the literature are given in the supporting information (Table S2)

\begin{tabular}{c|cccc}
\hline & Jin et al. $^{15}$ & Michael Krüsi $^{53}$ & Hanif et al. $^{54}$ & This study \\
\hline$\eta_{\text {all }}(\%)$ & - & 21.0 & 75.5 & 67.8 \\
\hline$\eta_{\text {sol-chem }}(\%)$ & $30-60$ & 66.0 & - & 86.8 \\
\hline
\end{tabular}

For the solar receiving area and heat flux used in this study, the concentrated solar thermal supply to the reactor is $4.82 \mathrm{~kW}$. For a biomass feed at the rate of $2 \mathrm{~g} / \mathrm{s}$, this gives a total energy of $2.41 \mathrm{MJ} / \mathrm{kg}$, which corresponds to enthalpy for pyrolysis of $2.07 \mathrm{MJ} / \mathrm{kg}$ on dry biomass basis (after subtracting the energy consumed in biomass water vaporization). This is close to the enthalpy value reported for fast pyrolysis of dry softwood (pine) in a fluidized bed reactor (1.64 $\pm 0.3 \mathrm{MJ} / \mathrm{kg})^{56}$. In conventional biomass pyrolysis reactors, the heat needed for the endothermic reaction is mainly satisfied by using direct or indirect external heating or by considering autothermal processing, e.g. coupling pyrolysis with combustion. In this study, if the heat is to be supplied by partial combustion of the feed biomass, then it is estimated that around $29 \%$ of this feed will be consumed in the combustion. If alternatively, the heat is supplied by electric heating, then this would be equivalent to $4.82 \mathrm{~kW}$. In this section it is of interest to show the reduction in greenhouse gas (GHG) emission that would be achieved by implementing the proposed solar pyrolysis option.

The emissions in the cases of biomass combustion and electric heating derived from conventional fuel are given by:

$$
\text { Emission from biomass combustion }=\frac{Q_{\text {demand }}}{H H V_{\text {biomass }}} \Upsilon_{c, i}
$$

Emission from electrcic heating $=Q_{\text {demand }} Y_{e, i}$

where $\Upsilon_{c, i}$ and $Y_{e, i}$ are the emission factors of each greenhouse gas $i$ and $Q_{\text {demand }}$ is the process thermal demand (see Table S3 in the supporting information for the values of $\Upsilon_{c, i}$ and $Y_{e, i}$ ). 


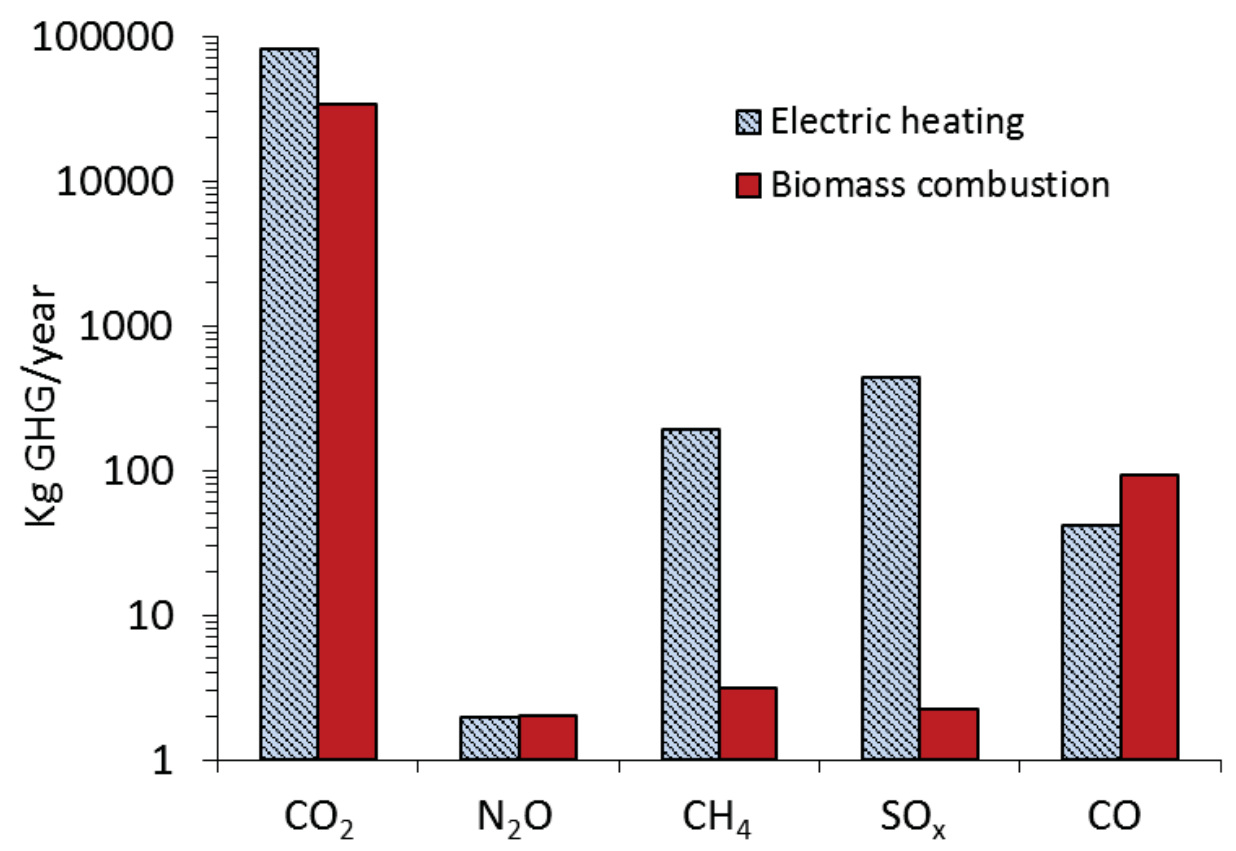

Figure 10. Greenhouse gas emissions associated with switch grass combustion and electricity in replacement of solar thermal heating option.

\section{Conclusions}

This study presented a computational fluid dynamic (CFD) model and performance analysis of a novel solar-thermal reactor for the conversion of biomass to bio-oil, gas and char through a pyrolysis process. The reactor is part of a proposed closed-loop pyrolysis-gasification process for the production of bio-oil and fuel gas. The CFD model was based on a Eulerian-Eulerian solution of multiphase flow coupled with heat transfer and chemical reaction equations to describe the flow hydrodynamic and rapid decomposition of the biomass.

For the operating condition considered in this study, the predicted product composition consisted of $51.5 \%$ bio-oil, $43.7 \%$ char and $4.8 \%$ non-condensable gas at an overall conversion 
efficiency of $67.8 \%$. These results, along with the clean and sustainable nature of the process, confirm the great potentials and competitiveness of the proposed reactor when compared to other types of solar and conventional reactors. Finally, it is hoped that the CFD model will help in future development, design and optimization of this novel hydride reactor.

\section{Supporting Information:}

Table S1. Constitutive equations used in the solution of the hydrodynamic model Table S2. Additional information on the types of reactors reported in the literature Table S3. Green House Gas (GHG) emission factors 


\section{Notation}

$C_{p}$

specific heat $\left(\mathrm{J} \mathrm{kg}^{-1} \mathrm{~K}^{-1}\right)$

$d_{i}$

diameter of solid phase $i$ (m)

D

reactor diameter (m)

E

activation energy $\left(\mathrm{kJ} \mathrm{mol}^{-1}\right)$

$\vec{g}$

gravity $\left(\mathrm{m} \mathrm{s}^{-2}\right)$

$h$

specific enthalpy $\left(\mathrm{kJ} \mathrm{kg}^{-1}\right)$

$h^{\prime}$

heat transfer coefficient $\left(\mathrm{W} \mathrm{m}^{2} \mathrm{~K}^{-1}\right)$

$H$

enthalpy $\left(\mathrm{kJ} \mathrm{kg}^{-1}\right)$

$\Delta H_{f, o}$

heat of formation at temperature $298 \mathrm{~K}_{\left(\mathrm{kJ} \mathrm{kg}^{-1}\right)}$

$\vec{J}_{i, g}$

diffusion flux of species $i\left(\mathrm{~kg} \mathrm{~m}^{-2} \mathrm{~s}^{-1}\right)$

$L$

reactor length (m)

$\dot{m}_{\text {in }}, \dot{m}_{\text {out }}$

mass flow of fed and entrained particles respectively ( $\mathrm{kg} \mathrm{s}^{-1}$ )

$\dot{m}_{s g}$

mass transfer due to drying $\left(\mathrm{kg} \mathrm{m}^{-3} \mathrm{~s}^{-1}\right)$

$N u_{s}$

Nusselt number of solid phase $i(-)$

$P$

pressure $(\mathrm{Pa})$

$\operatorname{Pr}$

Prandtl number (-)

$\vec{q}$

heat flux $\left(\mathrm{kJ} \mathrm{m}^{-2} \mathrm{~s}^{-1}\right)$

$Q_{g s}$

intensity of heat exchange between gas and solid $\left(\mathrm{kJ} \mathrm{m}^{-3} \mathrm{~s}^{-1}\right)$

$R_{g}, R_{S}$

interphase mass transfer term $\left(\mathrm{kg} \mathrm{m}^{-3} \mathrm{~s}^{-1}\right)$

$R e_{S}$

Reynolds number of solid phase $i(-)$

$S$

source of enthalpy due to chemical reaction $\left(\mathrm{kJ} \mathrm{m}^{-3} \mathrm{~s}^{-1}\right)$

$T$

temperature $\left({ }^{\circ} \mathrm{C}\right)$

$t$

time (s) 
$\vec{u}_{g}, \vec{u}_{s} \quad$ gas and solid velocity vector $\left(\mathrm{m} \mathrm{s}^{-1}\right)$

$Y_{i, g} \quad$ mass fraction of gas phase (-)

\section{Greek symbols}

$\begin{array}{ll}\alpha_{g}, \alpha_{s} & \text { volume fraction of gas and solid phase } i \text { respectively (-) } \\ \beta & \text { momentum exchange coefficient }\left(\mathrm{kg} \mathrm{m}^{-3} \mathrm{~s}^{-1}\right) \\ \gamma_{\Theta_{s}} & \text { collisional energy dissipation }\left(\mathrm{kg} \mathrm{m}^{-1} \mathrm{~s}^{-3}\right) \\ \eta_{\text {sep }}, \eta_{d} & \text { separation and devolatilization efficiencies (-) } \\ \eta_{\text {all }}, \eta_{\text {sol-chem }} & \text { overall energy and solar-chemical conversion efficiencies (-) } \\ \Theta_{s} & \text { Granular temperature of solid phase } i\left(\mathrm{~m}^{2} \mathrm{~s}^{-2}\right) \\ \kappa_{\Theta_{s}} & \text { Diffusion coefficient of granular energy }\left(\mathrm{kg} \mathrm{m}^{-1} \mathrm{~s}^{-1}\right) \\ \lambda_{s} & \text { Particle bulk viscosity }\left(\mathrm{kg} \mathrm{m}^{-1} \mathrm{~s}^{-1}\right) \\ \rho_{s}, \rho_{g} & \text { Solid and gas densities respectively }\left(\mathrm{kg} \mathrm{m}^{-3}\right) \\ \tau & \text { Solid residence time }(\mathrm{s}) \\ \overline{\bar{\tau}} & \text { Shear stress tensor }\left(\mathrm{kg} \mathrm{m}^{-1} \mathrm{~s}^{-2}\right)\end{array}$



open-loop solar chemical heat pipe. Energy 1992, 17 (12), 1189-1197.

(1) International Energy Agency. World Energy Outlook 2015; 2015.

(2) International Energy Agency. Key World Energy Statistics; Paris, 2016.

(3) Steinfeld, A.; Meier, A. Solar fuels and materials. Encycl. energy 2004, 5 (1), 623-637.

(4) Bridgwater, A.; Meier, D.; Radlein, D. An overview of fast pyrolysis of biomass. Org. Geochem. 1999, 30 (12), 1479-1493.

(5) Antal, M. J. Solar flash pyrolysis: Syngas from biomass. In Proceedings of the Solar Light Temperature Industrial Process Workshop; Atlanta,GA, 1978; p 345-351.

(6) Antal, M. J. Results of recent research on the use of pyrolysis/gasification reactions of biomass to consume solar heat and produce a useable gaseous fuel. In Proceedings of the Solar Thermal Test Facilities Users Association (STTFUA) Annual Meeting; Denver, CO, 1978.

Antal, M. J. Radiant flash pyrolysis of biomass. In Proceedings of the Solar Fuels Workshop; Albuquerque, NM, 1979; p 71-75.

Lédé, J. Pyrolysis and gasification of biomass in solar and simulated solar environments. The pioneering works of Michael J. Antal in the period 1976-1989. Energy \& Fuels 2016, 30 (10), 7896-7903.

Ingel, G.; Levy, M.; Gordon, J. Oil-shale gasification by concentrated sunlight: an Armelao, L.; Bettinelli, M.; Casarin, M.; Granozzi, G.; Tondello, E.; Vittadini, A. A theoretical and experimental investigation of the electronic structure of $\alpha$-Fe $2 \mathrm{O} 3$ thin films. J. Phys. Condens. Matter 1995, 7 (7), 299-305.

(11) Fletcher, E. Solarthermal processing: a review. Journal of Solar Energy Engineering 123 (2), May 2001.

(12) Steinfeld, A.; Palumbo, R. Solar thermochemical process technology, Phys. Sci. Technol. 2001, 15, 237-256.

(13) Ouagued, M.; Khellaf, A.; Loukarfi, L. Estimation of the temperature, heat gain and heat loss by solar parabolic trough collector under Algerian climate using different thermal oils. Energy Convers. Manag. 2013, 75, 191-201.

(14) Li, R.; Zeng, K.; Soria, J.; Mazza, G.; Gauthier, D.; Rodriguez, R.; Flamant, G. Product distribution from solar pyrolysis of agricultural and forestry biomass residues. Renew. Energy 2016, 89, 27-35.

(15) Jin, H.; Sui, J.; Hong, H. Prototype of middle-temperature solar receiver/reactor with parabolic trough concentrator. J. Sol. Energy Eng 129(4), 2007, 378-381. 
(16) Sui, J.; Liu, Q.; Dang, J.; Guo, D. Experimental investigation of methanol decomposition with mid-and low-temperature solar thermal energy. Int. J. Energy Res. 2011, 35 (1), 61-67.

(17) Morales, S.; Miranda, R.; Bustos, D.; Cazares, T.; Tran, H. Solar biomass pyrolysis for the production of bio-fuels and chemical commodities. J. Anal. Appl. Pyrolysis 2014, 109, 65-78.

(18) Anderson, J. R.; Reilley, D.; Seale, J.; Mendez, C.; Traum, M. J. A Slow Pyrolysis Reactor Utilizing Concentrated Solar Radiation to Drive a Thermo-Chemical Conversion of Carbonaceous Material. In 13th Annual Texas National McNair Scholars Research Conference; Denton,TX, 2011.

(19) Boutin, O.; Ferrer, M.; Lédé, J. Flash pyrolysis of cellulose pellets submitted to a concentrated radiation: experiments and modeling. Chem. Eng. Sci. 2002, 57 (1), 1525.

(20) Lédé, J. Solar thermochemical conversion of biomass. Sol. Energy 1999, 65 (1), 3-13.

(21) Wattana, A.; Rakwichian, W.; Ekasilp, W.; Tusnapucki, A. Velocity and Temperature Distribution of Flowing Water in a Solar Parabolic Trough Receiver. Int. J. Renew. Energy 2011, 6 (1).

(22) Xue, Q.; Dalluge, D.; Heindel, T.; Fox, R.; Brown, R. Experimental validation and CFD modeling study of biomass fast pyrolysis in fluidized-bed reactors. Fuel 2012, 97, 757769.

(23) Mellin, P.; Kantarelis, E.; Yang, W. Computational fluid dynamics modeling of biomass fast pyrolysis in a fluidized bed reactor, using a comprehensive chemistry scheme. Fuel 2014, 117 (A), 704-715.

(24) Boateng, A. A.; Mtui, P. L. CFD modeling of space-time evolution of fast pyrolysis products in a bench-scale fluidized-bed reactor. Appl. Therm. Eng. 2012, 33-34 (1), 190-198.

(25) Storey, B. L.; Monceaux, J. P. Extracting energy products from biomass using solar energy. GB 2458529, 2009.

(26) Jahirul, M.; Rasul, M.; Chowdhury, A.; Ashwath, N. Biofuels Production through Biomass Pyrolysis - A Technological Review. Energies 2012, 5 (12), 4952-5001.

(27) Huard, M.; Berruti, F.; Briens, C. Experimental Study of a Novel Fast Gas-Solid Separator for Pyrolysis Reactors. International Journal of Chemical Reactor Engineering, 2010, 8 (1), 1-22. 
(28) Yu, X.; Makkawi, Y.; Ocone, R.; Huard, M.; Briens, C.; Berruti, F. A CFD study of biomass pyrolysis in a downer reactor equipped with a novel gas-solid separator - I: Hydrodynamic performance. Fuel Process. Technol. 2014, 126, 366-382.

(29) Yu, X.; Hassan, M.; Ocone, R.; Makkawi, Y. A CFD study of biomass pyrolysis in a downer reactor equipped with a novel gas-solid separator-II thermochemical performance and products. Fuel Process. Technol. 2015, 133, 51-63.

(30) Boateng, A. A.; Daugaard, D. E.; Goldberg, N. M.; Hicks, K. B. Bench-scale fluidizedbed pyrolysis of switchgrass for bio-oil production. Ind. Eng. Chem. Res. 2007, 46 (7), 1891-1897.

(31) Launder, B.; Spalding, D. Lectures in mathematical models of turbulence. 1972.

(32) Yuanwei Zhanga, Zhongxi Chaob, Hugo A. Jakobsen, Modeling and simulation of hydrodynamics in double loop circulating fluidizedbed reactor for chemical looping combustion process, Volume 310, 1 April 2017, Pages 35-45

(33) Yanjun Guan, Jian Chang, Kai Zhang, BaodongWangb, Qi Sun, Three-dimensional CFD simulation of hydrodynamics in an interconnected fluidized bed for chemical looping combustion, Powder Technology 268 (2014) 316-328.

(34) Ariyaratne, WKHiromi1; Ratnayake, Chandana2; Melaaen, Morten C3 , EularianEularian approach for modeling dilute phase pneumatic conveying in a horizontal pipe, 12th International Conference on Bulk Materials Storage, Handling and Transportation (ICBMH 2016),

(35) Miao, Q.; Zhu, J.; Barghi, S.; Wu, C.; Yin, X.; Zhou, Z. Modeling biomass gasification in circulating fluidized beds. Renew. Energy 2013, 50, 655-661.

(36) Dupont, C.; Boissonnet, G.; Seiler, J.-M.; Gauthier, P.; Schweich, D. Study about the kinetic processes of biomass steam gasification. Fuel 2007, 86 (1), 32-40.

(37) Gunn, D. Transfer of heat or mass to particles in fixed and fluidised beds. Int. J. Heat Mass Transf. 1978, 21 (4), 467-476.

(38) ANSYS Fluent. Ansys fluent theory guide: Version 15.0. Ansys Inc.

(39) Pasangulapati, V. Devolatilization characteristics of cellulose, hemicellulose, lignin and the selected biomass during thermochemical gasification: experiment and modeling studies, 2012.

(40) Johnson, P.; Jackson, R. Frictional-collisional constitutive relations for granular materials, with application to plane shearing. J. Fluid Mech. 1987, 176, 67-93.

(41) Makkawi, Y.; Ocone, R. A model for gas-solid flow in a horizontal duct with a smooth merge of rapid-intermediate-dense flows. Chem. Eng. Sci. 2006, 61 (13), 4271-4281. 
(42) Herbreteau, C.; Bouard, R. Experimental study of parameters which influence the energy minimum in horizontal gas-solid conveying. Powder Technol. 2000, 112 (3), 213-220.

(43) A. Passalacqua, R.O. Fox, Advanced continuum modeling of gas-particle flows beyond the hydrodynamic limit, Applied Mathematical Modeling 35 (2011) 1616-1627.

(44) Elewuwa, F.; Makkawi, Y. A computational model of hydrogen production by steam reforming of dimethyl ether in a large scale CFB reactor. Part II: Parametric analysis. Int. J. Hydrogen Energy 2016, 41 (44), 19819-19828.

(45) Ghirelli, F.; Hermansson, S.; Thunman, H.; Leckner, B. Reactor residence time analysis with CFD. Prog. Comput. Fluid Dyn. 2006, 6 (4/5), 241-247.

(46) Yang, H.; Yan, R.; Chen, H.; Lee, D. H.; Zheng, C. Characteristics of hemicellulose, cellulose and lignin pyrolysis. Fuel 2007, 86 (12-13), 1781-1788.

(47) Zeng, K.; Gauthier, D.; Li, R.; Flamant, G. Solar pyrolysis of beech wood: Effects of pyrolysis parameters on the product distribution and gas product composition. Energy 2015, 93, 1648-1657.

(48) Joardder, M.; Halder, P.; Rahim, A.; Paul, N. Solar assisted fast pyrolysis: a novel approach of renewable energy production. J. Eng. 2014, 2014, 1-4.

(49) Authier, O.; Ferrer, M.; Mauviel, G. Wood fast pyrolysis: comparison of Lagrangian and Eulerian modeling approaches with experimental measurements. Ind. Eng. ... 2009, 48 (10), 4796-4809.

(50) Li, X.T.; Grace, J. R.; Watkinson, A. P.; Lim, C. J.; Ergudenler, A. E. Equlibrium modeling of gasification: a free energyminimization approach and its application to a circulati

(51) Channiwala, S. A.; Parikh, P. P. A unified correlation for estimating HHV of solid, liquid and gaseous fuels. Fuel 2002, 81 (8), 1051-1063.

(52) Goswami, Y. Alternative Energy in Agriculture. Alternative Energy in Agriculture. CRC Press: Boca Raton, FL 1986, pp 83-102.

(53) Krüsi, M. Heat Transfer Enhancement in a Solar Biomass Gasifier, ETH Zurich, 2011, Vol. 2.

(54) Hanif, M.; Capareda, S.; Iqbal, H.; Arazo, R.; Baig, M. Effects of Pyrolysis Temperature on Product Yields and Energy Recovery from Co-Feeding of Cotton Gin Trash, Cow Manure, and Microalgae: A Simulation. PLoS One 2016, 11 (7), 1-11.

(55) Lédé, J. Comparison of contact and radiant ablative pyrolysis of biomass. J. Anal. Appl. Pyrolysis 2003, 70 (2), 601-618. 
(56) Daugaard, D. E; Brown, R. C. Enthalpy for Pyrolysis for Several Types of Biomass, Energy and Fuels 2003, 17, 934-939

(57) Lun, C. K. K.; Savage, S. B.; Jeffrey, D. J.; Chepurniy, N. Kinetic theories for granular flow: inelastic particles in Couette flow and slightly inelastic particles in a general flowfield. J. Fluid Mech. 1984, 140 (1), 223-256.

(58) Syamlal, M.; Rogers, W.; O’Brien, T. MFIX documentation: Theory guide note. National Energy Technology Laboratory, Department of Energy, Technical Note DOE/METC-95/1013 and NTIS/DE95000031.

(59) Saidur, R.; Abdelaziz, E. A review on biomass as a fuel for boilers. Renew. Sustain. Energy Rev. 2011, 15 (5), 2262-2289.

(60) Deru, M.; Torcellini, P. Source energy and emission factors for energy use in buildings; Golden, CO, 2007. 